James W. Wansley, CFA

University of Tennessee

William R. Lane, CFA

Louisiana State University

Phillip R. Daves

University of Tennessee

\title{
Initial Dividends and Implications for Investors
}

The Research Foundation of

The Institute of Chartered Financial Analysts 


\section{Research Foundation Publications}

Active Currency Management

by Murali Ramaswami

Analysts' Earnings Forecast Accuracy in Japan and the United States

by Robert M. Conroy, Robert S. Harris, and Young S. Park

Bankruptcy Prediction Using Antificial Neural Systems

by Robert E. Dorsey, Robert 0. Edmister, and John D. Johnson

Canadian Stocks, Bonds, Bills, and Inflation: 1950-1987

by James E. Hatch and Robert E. White

Company Performance and Measures of Value Added by Pamela P. Peterson, CFA, and David R. Peterson

Corporate Bond Rating Drift: An Examination of Credit Quality Rating Changes Over Time

by Edward I. Altman and Duen Li Kao

Corporate Governance and Firm Performance by Jonathan M. Karpoff, M. Wayne Marr, Jr., and Morris G. Danielson

Currency Management: Concepts and Practices by Roger G. Clarke and Mark P. Kritzman, CFA

Earnings Forecasts and Share Price Reversals by Wermer F.M. De Bondt

Economically Targeted and Social Investments: Investment Management and Pension Fund Performance

by M. Wayne Marr, John R. Nofsinger, and John L. Trimble

Equity Trading Costs

by Hans R. Stoll

Ethics, Fairness, Efficiency, and Financial Markets by Hersh Shefrin and Meir Statman

Ethics in the Investment Profession: A Survey by $\mathrm{E}$. Theodore Veit, CFA, and Michael $\mathrm{R}$. Murphy, CFA

Ethics in the Investment Profession: An International Survey

by H. Kent Baker, CFA, E. Theodore Veit, CFA, and Michael R. Murphy, CFA
The Founders of Modern Finance: Their PrizeWinning Concepts and 1990 Nobel Lectures

Franchise Value and the Price/Earnings Ratio by Martin L. Leibowitz and Stanley Kogelman

Fundamental Considerations in Cross-Border Investment: The European View

by Bruno Solnik

Global Asset Management and Performance Attribution

by Denis S. Karmosky, and Brian D. Singer, CFA

Initial Public Offerings: The Role of Venture Capitalists

by Joseph T. Lim and Anthony Saunders

Interest Rate and Currency Swaps: A Tutorial by Keith C. Brown, CFA, and Donald J. Smith

Managed Futures and Their Role in Investment Portfolios

by Don M. Chance, CFA

The Modern Role of Bond Covenants by Ileen B. Malitz

A New Perspective on Asset Allocation by Martin L. Leibowitz

Options and Futures: A Tutorial

by Roger $\mathrm{G}$. Clarke

The Poison Pill Anti-Takeover Defense: The Price of Strategic Deterrence

by Robert F. Bruner

\section{A Practitioner's Guido to Factor Models}

Predictable Time-Varying Components of International Asset Returns

by Bruno Solnik

The Role of Risk Tolerance in the Asset Allocation Process: $A$ New Perspective

by W.V. Harlow III, CFA, and Keith C. Brown, CFA

Selecting Superior Securities

by Marc R. Reinganum

Time Diversification Revisited

by William Reichenstein, CFA, and Dovalee Dorsett 


\section{Initial Dividends and Implications for Investors}


(C) 1996 The Research Foundation of The Institute of Chartered Financial Analysts

All rights reserved. No part of this publication may be reproduced, stored in a retrieval system, or transmitted, in any form or by any means, electronic, mechanical, photocopying, recording, or otherwise, without the prior written permission of the copyright holder.

This publication is designed to provide accurate and authoritative information in regard to the subject matter covered. It is sold with the understanding that the publisher is not engaged in rendering legal, accounting, or other professional service. If legal advice or other expert assistance is required, the services of a competent professional should be sought.

ISBN 978-0-943205-37-3

Printed in the United States of America

December 1996

\section{Editorial Staff}

Elizabeth A. Collins Editor

Fiona D. Russell Assistant Editor
Jaynee M. Dudley Manager, Educational Products

Diane B. Hamshar Typesetting/Layout 


\section{The Research Foundation's}

mission is to identify, fund, and publisf research that is relevant to the AIMR Global Body of Knowledge and useful for AIMR member investment practitioners and investors.

The Research Foundation of

The Institute of Chartered Financial Analysts

$$
\text { P.O. Box } 3668
$$

Charlottesville, Virginia 22903

$$
\text { U.S.A. }
$$

Telephone: 804-980-3655

Fax: 804-980-3634

E-mail: r@aimr.org

World Wide Web: http://www.aimr.org/aimr/research/research.html 


\title{
Biographies of Authors
}

\begin{abstract}
James W. Wansley, CFA, is head of the Finance Department at the College of Business Administration at the University of Tennessee and holds the Clayton Homes Chair of Excellence in Finance. He is a former director of the Financial Institutions Center at the University of Tennessee and previously served on the finance faculty at Louisiana State University. His research has focused on the market for corporate control, especially the method of payment used in acquisitions, corporate financial policies, and bank capital issues. Professor Wansley serves as an associate editor for the Journal of Financial Research and the Financial Review. He holds a B.A. from Emory University, an M.B.A. from the University of Georgia, and a Ph.D. from the University of South Carolina.
\end{abstract}

William R. Lane, CFA, is professor of finance at Louisiana State University. His recent research addresses issues in dividend policy, mergers and acquisitions, and the regulation of financial institutions. He has served as president of the Eastern Finance Association, vice president of the Financial Management Association, and director for the Southern Finance Association. Professor Lane holds a B.A. in mathematics, an M.B.A. from Lehigh University, and a Ph.D. from the University of North Carolina.

Phillip R. Daves is an associate professor of finance at the College of Business Administration at the University of Tennessee. His research has included risk management, asset pricing, valuation, and derivative securities. Professor Daves holds a B.A. in economics from Davidson College, an M.S. in mathematics from the University of North Carolina at Chapel Hill, and a Ph.D. in business administration (finance) from the University of North Carolina at Chapel Hill. 


\section{Foreword}

In a recent edition of their celebrated textbook Principles of Corporate Finance, Richard Brealey and Stewart Myers offer the following conclusion:

We spent [considerable attention] on dividend policy without being able to resolve the dividend controversy. Many people believe dividends are good, others believe they are bad, and still others believe they are irrelevant. If pressed, we stand somewhere in the middle, but we can't be dogmatic about it.

Indeed, there are few topics in financial economic research where theory meets practice so unsuccessfully as where efforts are made to explain how and why firms pay dividends to their stockholders. From the pioneering irrelevance propositions of Franco Modigliani and Merton Miller to the more recent work of Frank Easterbrook suggesting that dividends are paid in order to reduce agency costs, much has been written on the topic without producing anything close to a definitive conclusion. Perhaps Fisher Black, in his article "The Dividend Puzzle," said it best: "What should corporations do about dividend policy? We don't know."

The essence of the dividend puzzle appears to be that there is no clear-cut formula that advises a corporation how to set its payout policy. Although certain stockholders might choose to receive most or all of the expected compensation from their investments packaged in the form of periodic cash payments, many others would prefer to have the company reinvest those funds if it can do so more profitably than the investors' next best alternative. Further complicating this decision are such factors as the potentially unpredictable nature of the firm's future capital needs and shifts in the personal and corporate tax rates borne by the shareholders. To say the least, we have a very incomplete picture of the intellectual underpinnings of this basic-and seemingly innocuous-corporate decision. The good news is that every additional piece of theoretical or empirical evidence pushes us a little closer to solving the puzzle.

In this monograph, Professors James Wansley, William Lane, and Phillip Daves provide us with just such a gentle shove. In particular, rather than tackling the entire dividend payout issue, they focus on the consequences of a company's decision to initiate dividend payments. Their empirical evidence supports two possible reasons for this phenomenon: (1) Some companies begin paying dividends only if they think they can sustain them in the future, which implies that investors might be able to infer something positive about a company's earnings prospects from the initiation. (2) Some companies initiate dividends 
because of a general decline in investment opportunities; this category would include those maturing firms returning excess free cash flow to their stockholders rather than misallocating it to substandard projects.

Although neither of these findings can be considered pathbreaking, they are consistent with what we know from the existing literature about all dividend programs. For instance, agency theory holds that by reducing free cash flow through dividend payments, managers increase the possibility that they will have to raise additional investment capital in public markets, which would force a periodic external monitoring of their activities. On the other hand, signaling theory holds that managers privy to "inside" knowledge about the firm's earnings prospects can bridge the information gap with investors by committing to a stream of payments that, as tradition and previous research tell us, will be costly to reduce in the future. Thus, the authors' initial findings provide corroboration for what we already know about why firms pay dividends.

Given this prior evidence, the more interesting question addressed in the monograph is: What can investors do with this new information about dividend initiations? It is in pursuing an answer to this question that the authors' most important contributions emerge. Specifically, Wansley, Lane, and Daves chronicle how the market reacts when a company begins to pay dividends and how astute investors might profit from interfirm differences in these reactions. Their findings about this latter point are encouraging, although they must be interpreted with a fair degree of caution. The trick, it seems, is being able to identify which non-dividend-paying companies are likely to begin payments in the near future. The authors' data offer considerable guidance in initiation identification (e.g., concentrate on firms with decreasing growth rates and investment opportunities), the process is hardly an exact science.

This research has several appealing qualities. Chief among them is that it is written with the manager in mind, a point evident in the patience with which the authors summarize the existing academic literature in order to establish a context for their findings. In addition, the authors help us understand nuances in the role that dividend initiations play within larger dividend policy. Finally, Wansley, Lane, and Daves also provide a strong link between investment research and practice and, in the process, give investors some hope that markets are not completely efficient-if the proper analysis can be produced. For all of these reasons, the Research Foundation is pleased to have supported this work, and we recommend it to your attention.

Keith C. Brown, CFA Research Director The Research Foundation of the Institute of Chartered Financial Analysts 


\section{Preface}

The effect of alternative corporate dividend policies on investors is not well understood. Successful firms exist that have never paid dividends, that pay dividends irregularly, and that have a long history of steady dividend payout. Some firms have paid dividends up to the point that they declared bankruptcy. Thus, success in a market sense does not appear to require a specific dividend policy, but this observation does not imply that dividend policy is irrelevant to the market. Changes in corporate dividend policy frequently have a substantial effect on the market value of the firm.

Perhaps no change in dividend policy is less understood than the decision to begin paying dividends. Studies of the market's reaction to the announcement of an initial dividend report a statistically significant average increase in stock price of 3-4 percent. The authors of these analyses typically interpret their results in terms of either agency theory (incomplete contracting) or information signaling. The usual conclusion is that the announcement conveys to the market positive information about the future earnings and cash flows available to the firm's shareholders.

In this monograph, we examine the implications for the investor of a firm's decision to begin paying dividends. Using both new and existing empirical studies, we explore the market effects of dividend initiation, firm-specific factors that may cause firms to initiate dividends, and the effects of those factors on investor returns.

The monograph is directed toward the practicing financial analyst or portfolio manager. The reader is assumed to have a basic knowledge of corporate finance and some understanding of empirical methods in finance and economics. Although not all the methodological details are covered, references to more technical details are included for the interested reader.

A number of individuals assisted in the research process for this final product. We would like to thank faculty members of the Finance Department at the University of Tennessee for their careful reading of earlier drafts of the monograph. We are also most appreciative of financial support from the Research Foundation of the Institute of Chartered Financial Analysts.

James W. Wansley, CFA

Knoxville, Tennessee

William R. Lane, CFA

Baton Rouge, Louisiana
Phillip R. Daves

Knoxville, Tennessee

Fall 1996 



\section{Initial Dividends and Implications for Investors}

When a company changes its dividend payment, the market value of the company frequently changes substantially. Numerous studies have documented large positive announcement effects, on average, in response to dividend increases and even larger negative announcement effects for dividend decreases. The announcement of an initial dividend marks a fundamental change in the company's dividend policy and thus represents more than an increase in the payout.

Annual dividend increases are often expected for companies that regularly pay dividends, and dividend decreases most often result from prolonged financial distress. Dividend initiations, however, are likely to be a surprise. And because individual investors are likely to have preferences regarding the dividend policies of the companies in which they hold shares, the decision to initiate a dividend has special implications for the investor clientele of initiating companies.

The nature of the information revealed to the market by the announcement of the initial dividend is not clear. The traditional residual view of dividends suggests that dividend policy depends on the company's investment opportunities: Dividends are paid only after the company's investment opportunities have been evaluated and the resulting need for funds determined. In this interpretation, a dividend initiation suggests that the company's set of investment opportunities and its future growth potential have shrunk and that surplus funds are now available. If this interpretation is correct, then the market response to the dividend-initiation decision should be negative.

On the other hand, recent evidence suggests a signaling motive behind dividend initiations and other dividend changes. In this interpretation, management uses increases in dividends, including initiation of a dividend, to suggest that future cash flows will be greater than previously anticipated. Although the cash dividend signal is expensive, it is credible. Asquith and Mullins (1986) express the credibility of dividend signals succinctly:

Critics of signaling through dividends raise a simple question. In view of the tax burden and other costs associated with dividends, aren't there equally effective, less costly ways to convey information? There are reasons for the 
efficacy of dividends as signals. Dividend announcements are backed by hard, cold cash. The company must generate this cash internally or convince the capital markets to supply it.

An extensive body of literature addresses changes in stock price in response to announcements of changes in dividends. Aharony and Swary (1980), Asquith and Mullins (1983), Eades, Hess, and Kim (1985), Kane, Lee, and Marcus (1984), Pettit (1972), and Wansley, Sirmans, Shilling, and Lee (1991), among others, document similar dividend-announcement effects.

The empirical evidence on the market impact of the dividend-initiation announcement shows that the average response is significantly positive. Asquith and Mullins (1983), for example, found an excess return of approximately 4 percent on the two days surrounding a company's announcement of its intention to initiate dividends.

This market effect is, of course, the average effect on the companies announcing the dividend initiation. Considerable cross-sectional variation exists in the magnitude of the dividend-initiation effect. Despite the positive average market effect of a dividend initiation, almost one-third of the companies in Asquith and Mullins's sample lost value around the time of announcement of a dividend initiation. Asquith and Mullins reported that the two-day excess returns around the announcement date of the dividend initiation in their study ranged from -18 percent to as large as 30 percent. We found similar results in our sample of dividend initiations from 1972 through 1988 . The average marketadjusted effect extended from a minimum of -26.1 percent to a maximum of 78.6 percent. Thus, the evidence suggests that the decision to initiate dividends has different market implications for different companies. Some companies appear to benefit by an increased share price; others suffer a price reduction.

The purpose of this monograph is to address the implications for investors of a company's decision to begin paying dividends. We examine the market effects of dividend initiation, consider several company-specific factors that may cause companies to initiate dividends, and look into the effects of those factors on investor returns.

The monograph addresses several related questions. First, what are the market effects of dividend initiations? Second, considering financial and market characteristics, can distinct groupings or clusters of companies that initiate dividends be identified? Third, if these distinct clusters of companies exist, do they offer significantly different levels of return to investors?

The material is organized as follows. The first section discusses prior evidence on dividend initiations. The next section describes the data used in this study and previews the market effects of dividend initiations. This section also presents the results of a cluster analysis of dividend-initiating companies 
based on company financial and market characteristics. This analysis is followed by application of a logistic regression model to determine company attributes that lead to the decision to initiate dividends. The monograph then turns to an analysis of alternative portfolio strategies designed to take advantage of the findings about market responses to dividend-initiation announcements and the characteristics of dividend-initiating companies. The final section summarizes the findings.

\section{Prior Evidence on Dividend Initiations}

The meager empirical literature on dividend initiation consists primarily of event studies (and variants of event studies) of the reaction of stock prices to a dividend announcement. Although we start this section with the dividend controversy in general terms, our intent is not to provide a complete survey of the dividend literature. For that, we refer the reader to the extensive reviews by Ang (1987) and Allen and Michaely (1994). Instead, in this section, we provide some background on the likely market effects of dividend initiations and consider the suggested bases for such reactions.

The Dividend Controversy. The effect of dividend policy on share price is a controversial topic among academics, analysts, and portfolio managers. Early studies established the intuitive argument that information revealed by changes in dividends should be associated with changes in operating earnings and cash flows. Lintner (1956), in a survey of managers of dividend-paying companies, found evidence linking dividends to past earnings trends. Fama and Babiak (1968) supported Lintner's survey by finding that dividends are a function of lagged earnings.

Miller and Modigliani (1961) were among the first to analyze rigorously the impact of dividend policy on company value. They showed that, under certain restrictions, the value of the company is independent of its dividend policy. Miller and Modigliani, although arguing that dividend policy should be irrelevant to shareholders in perfectly efficient capital markets, were also aware that the market is not indifferent to dividends, and they accepted that a dividend announcement can reveal management's expectations about future earnings and cash flows. They recognized that the market would respond to changes in dividends if the assumption that all market participants, including corporate insiders, have equal and costless access to information were relaxed. They referred to this phenomenon as the "informational content of dividends":

That is, where a company has adopted a policy of dividend stabilization with a long established and generally appreciated "target payout ratio," investors are likely to (and have good reason to) interpret a change in the dividend rate as a change in management's views of future profit prospects for the company. 
The dividend change, in other words, provides the occasion for the price change though not its cause, the price still being solely a reflection of future earnings and growth opportunities.

Signaling Information with Dividends. Miller and Rock (1985) extended earlier models by explicitly recognizing the signaling potential of announcements of dividend changes ("the informational content of dividends"). Their model can be separated into two components. One is the dollar-for-dollar effect of the dividend surprise itself. The other effect relates to the persistence in earnings. The dividend announcement serves to provide the missing piece of the sources-equal-uses constraint that the market needs to establish the company's current earnings. That earnings figure is used by the market as the basis for estimating future earnings. Thus, the importance of the dividend signal is the additional information it provides, which allows analysts to improve their estimates of future earnings. It is earnings that are important, not dividends per se.

In contrast, Born, Moser, and Officer (1988) examined growth in earnings per share subsequent to dividend changes and failed to support dividend signaling. Shen (1994) found that, on average, security analysts revise their earnings forecasts significantly upward in the month of an initial dividend announcement. This finding is consistent with the more general positive association between dividend increases and changes in analysts' forecasts reported by Ofer and Siegel (1987). More than half of the companies in Shen's study, however, exhibited no change in average earnings forecasts in the month of the announcement. Thus, in the majority of his cases, the initial dividend announcement was not interpreted as new information about the level of future earnings.

Agency Models of Dividends. Jensen and Meckling (1976) are generally credited with incorporating agency theory into modern finance. ${ }^{1}$ Agency models approach dividends as a means of creating and resolving conflicts of interest between shareholders and other parties contracting with the company. Consequently, the implications for changes in the characteristics of the company are broader than those associated with signaling theories and earnings information models.

Agency theory as framed by Easterbrook (1984) and Jensen (1986) views dividends as a means of reducing conflict between shareholders and managers by reducing the cash flow at management's discretion ("free cash flow"). Iang and Litzenberger (1989) tested this implied association and found support for the free cash flow hypothesis.

\footnotetext{
${ }^{1}$ Jensen and Meckling (1976) is abstracted as a classic study in investment theory on pp. 4-7 in the Winter 1996 issue of The CFA Digest.
} 
Empirical analyses based on agency theory also frequently consider insider ownership. Rozeff (1982) reported dividend payout to be negatively correlated with past sales growth, systematic risk (beta), and insider ownership and to be positively correlated with number of shareholders. Born (1988) found the stock price reaction to the announcement of an initial dividend to be positively correlated with insider ownership.

Although the meaning of "insider ownership" is clear in Jensen and Meckling's theory, its measurement is not. A wide variety of related measures have appeared, but no "correct" measure has been forthcoming. Thus, the interpretation of the preceding correlations is unclear.

Market Effects of Dividend Initiations. Asquith and Mullins (1983) were the first to examine the market effects of dividend initiations. They found that companies initiating dividends experience large positive excess returns and that these returns are generally larger than those of companies that increase existing dividends. Asquith and Mullins reported the average excess return for the 160 companies in their sample to be 3.7 percent during the two days surrounding the announcement day.

Beginning with Asquith and Mullins, researchers have attempted, usually based on either signaling or agency theory, to relate the market reaction to various characteristics of companies making the announcement. Asquith and Mullins reported that the large positive excess returns around the announcement of the dividend-initiation decision do not depend on other events, such as earnings announcements, and that the size of the excess return is positively related to the size of the initial payment.

Healy and Palepu (1988, 1989) and Venkatesh (1989) examined the relationship between initial dividends and subsequent earnings announcements. Healy and Palepu found that companies that initiate dividends have positive earnings surprises in the year before and the three years after the dividend initiation. Venkatesh found that the volatility of daily returns decreases after a dividend initiation and that most of the decrease is attributable to a decrease in company-specific risk. Thus, investors and analysts could be using the dividend-initiation decision as management's signal of higher, or less risky, future cash flows.

Both Venkatesh and Healy and Palepu show that the informational content of quarterly earnings announcements is smaller after the introduction of cash dividends. Thus, dividend announcements appear to be at least a partial substitute for the information about the company previously revealed in earnings announcements. 
Recently, Michaely, Thaler, and Womack (1995) examined market reactions to dividend initiations and omissions by exploring both the immediate price effects around the announcement and the long-term postannouncement price performance. They tested whether the effects of dividend-initiation and dividend-omission announcements represent an overreaction or a gradual drift toward a new, higher price level. They found that prices of dividendinitiating companies continue to rise for at least 36 months following the original announcement. The three-year excess return they found was more than 24 percent. The authors then developed a trading strategy based on a long position in dividend-initiating companies and a short position in the CRSP (Center for Research in Security Prices) equal-weighted index. This portfolio, with zero net investment, had an average return of 9.7 percent for 1964 through 1988, and the returns were positive in 22 of the 25 years.

\section{Market Performance of Dividend Initiators}

This monograph reports new evidence on the market effects of dividend initiations, with particular emphasis on the cross-sectional variation in the announcement effects. The results are based on more than 1,000 companies that traded on the New York Stock Exchange (NYSE), the American Stock Exchange (Amex), or the over-the-counter (OTC) markets and that announced their first cash dividend between 1972 and 1988. In order to be included in the sample, the company also had to be included in the CRSP daily returns and master files and the dividend initiation had to be listed in Moody's Dividend Record as the first cash dividend.

Figure 1 shows the distribution of dividend initiations by year. Dividend initiations peaked during the 1970 s, declined during the early 1980 s, and rose again in the late $1980 \mathrm{~s}$. The greatest number of initiations, 133 , occurred in 1975 , and the least, 16, occurred in 1983.

The market performance of dividend-initiating companies during the two years surrounding the dividend initiation is illustrated in Figure 2. Returns plotted in Figure 2 are cumulative mean-adjusted returns: Each company's mean return was determined from Trading Day -250 through Trading Day +250 relative to the dividend announcement. Throughout this section, excess returns are defined on the basis of a market model in which the parameters of the model are estimated from Day -250 to Day -60 , relative to the announcement day. We excluded the 10-day window before the announcement from the estimation period in order to limit exposure of the returns to information leaks prior to the announcement. Details of the estimation procedure are in Brown and Warner (1985). 
Figure 1. Distribution of Initial Dividend Announcements by Year of Initiation, 1972-88

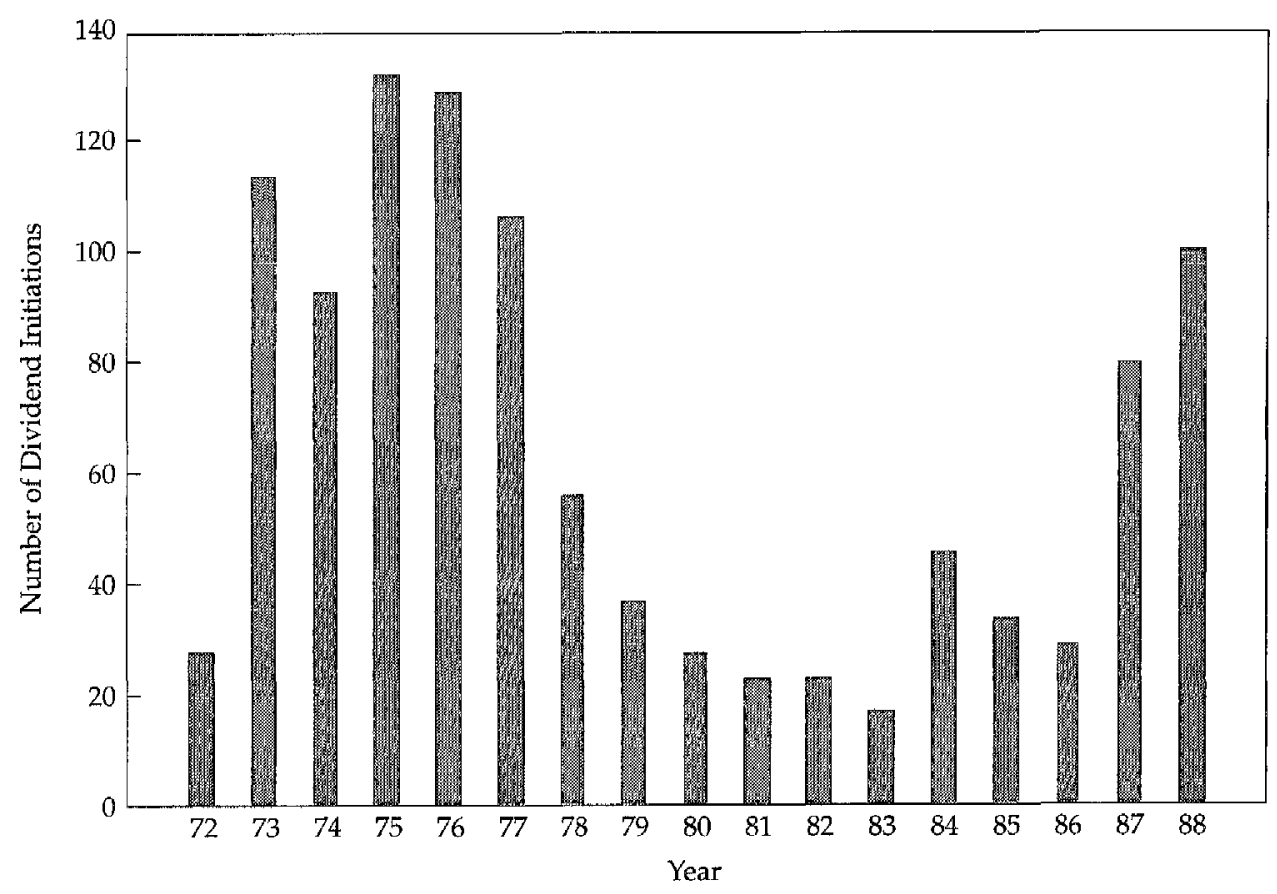

The pattern of excess returns is very different for NYSE- or Amex-traded companies from the pattern for companies that trade OTC. ${ }^{2}$ NYSE/Amex companies experienced excess returns of 3.6 percent during the 245 trading days ending 5 days prior to the announcement. Although returns for these companies were positive during the days surrounding the announcement, the cumulative excess returns declined 3.4 percent following the announcement, offsetting the earlier run-up. The OTC companies performed much better, both before the initial dividend announcement and following the announcement. For the 245 trading days ending 5 days prior to the announcement, the cumulative mean-adjusted returns totaled 19.3 percent; the returns exceeded 40 percent during the remaining 255 trading days.

Market effects immediately surrounding the initial dividend announcement

${ }^{2}$ A company was included as a NYSE/Amex company if it last traded on the NYSE or Amex and was included as an OTC company if it last traded on the OTC as indicated on the CRSP combined NYSE/Amex/OTC file. 
Figure 2. Market Performance of Dividend-Initiating Firms for Two Years Surrounding Dividend Initiation

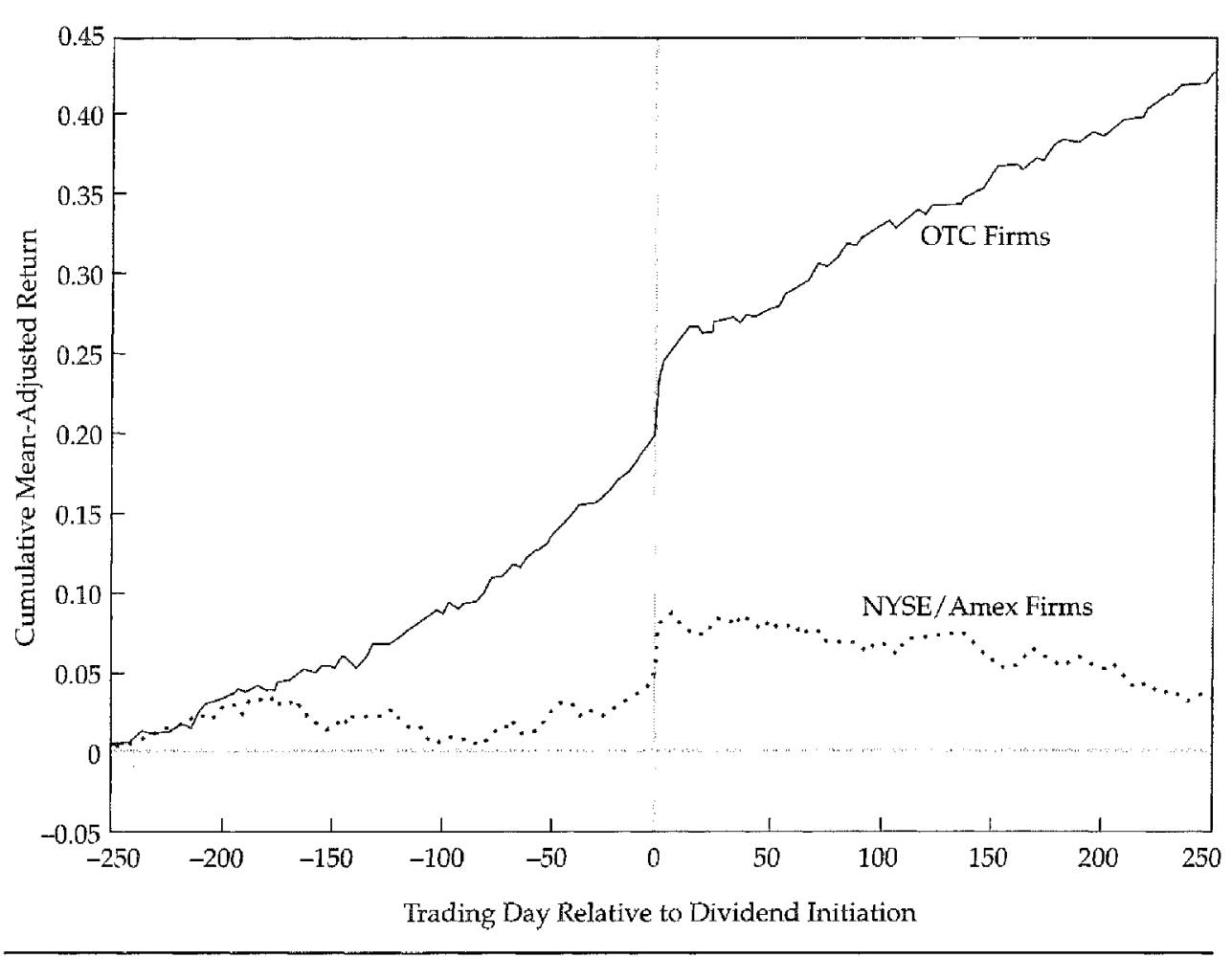

are very similar for NYSE/Amex and OTC companies. Table 1 displays the market effects of the announcements and their significance levels. NYSE/Amex companies earned an excess return of 3.2 percent, and OTC companies earned 3.3 percent, during the three-day interval surrounding the announcement. The $z$-statistics test the null hypothesis that the daily excess return equals zero. A value for the $z$-statistic larger than 2.0 suggests that the excess return for that day is statistically different from zero. All of the $z$-statistics during the three-day interval surrounding the dividend announcement are highly significant, and the significant $z$-statistics prior to the announcement suggest some anticipation. The columns headed "Percent Positive" indicate the percentage of daily residuals that are positive. With few exceptions, including the dividend announcement and the following day, approximately 50 percent of the daily prediction errors are positive and 50 percent are negative. Figure 3 depicts a bar graph of the daily excess returns during 41 days surrounding the announcement.

Although the average response to the dividend announcement is highly 
Table 1. Dailly Abnormal Returns for Dividend-Initiating Firms, 1972-88

\begin{tabular}{|c|c|c|c|c|c|c|}
\hline \multirow[b]{2}{*}{$\begin{array}{l}\text { Day Relative to } \\
\text { Announcement } \\
\text { Day }\end{array}$} & \multicolumn{3}{|c|}{$\begin{array}{l}\text { NYSE/Amex Sample } \\
\qquad(n=414)\end{array}$} & \multicolumn{3}{|c|}{$\begin{array}{l}\text { OTC Sample } \\
(n-663)\end{array}$} \\
\hline & $\begin{array}{l}\text { Average } \\
\text { Abnormal } \\
\text { Return (\%) }\end{array}$ & $z$-Statistic & $\begin{array}{l}\text { Percent } \\
\text { Positive }\end{array}$ & $\begin{array}{l}\text { Average } \\
\text { Abnormal } \\
\text { Return (\%) }\end{array}$ & $z$-Statistic & $\begin{array}{l}\text { Percent } \\
\text { Positive }\end{array}$ \\
\hline-20 & 0.131 & 0.531 & 48.3 & 0.167 & 1.497 & 46.9 \\
\hline-10 & -0.001 & -0.354 & 47.8 & 0.163 & 1.464 & $45.3^{* *}$ \\
\hline-5 & 0.189 & 1.158 & 49.0 & 0.097 & 1.306 & 46.6 \\
\hline-4 & 0.341 & 2.289 & 51.5 & -0.030 & 1.221 & $45.5^{\circ}$ \\
\hline-3 & 0.034 & 0.449 & 47.3 & 0.052 & 1.986 & 46.9 \\
\hline-2 & 0.079 & 0.734 & 48.8 & 0.538 & 4.905 & 51.6 \\
\hline-1 & 0.593 & 3.370 & 50.0 & 0.661 & 7.222 & 52.7 \\
\hline 0 & 1.430 & 8.450 & $58.7^{\cdots \cdots}$ & 1.453 & 15.514 & $55.7^{\cdots \cdots}$ \\
\hline+1 & 1.203 & 6.705 & $56.3^{\cdots}$ & 1.184 & 11.859 & $54.3^{* *}$ \\
\hline+2 & 0.269 & 1.058 & 50.7 & 0.538 & 4.905 & 51.6 \\
\hline+3 & 0.060 & 0.135 & 49.8 & 0.186 & 2.590 & 48.8 \\
\hline+4 & -0.105 & -0.125 & $41.8^{n+\infty}$ & 0.341 & 3.750 & 50.2 \\
\hline+5 & 0.073 & 0.889 & 49.0 & 0.381 & 3.881 & 50.6 \\
\hline+10 & -0.139 & -0.521 & 48.8 & -0.020 & 0.268 & $44.5^{* *}$ \\
\hline+20 & -0.246 & -1.182 & $44.4^{*-}$ & -0.033 & -0.176 & 46.1 \\
\hline
\end{tabular}

** Significantly different from 50 percent at the 5 percent level (one-tailed test).

${ }^{* * *}$ Significantly different from 50 percent at the 1 percent level (one-tailed test).

significant, the Percent Positive column in Table 1 indicates that fewer than 60 percent of the companies experience positive excess returns on any of the days immediately surrounding the dividend announcement. If the initial dividend decision conveys information about likely future prospects for earnings or market performance, clearly the signal differs among companies. Table 2 shows the distribution of the cumulative abnormal (or excess) returns (CARs) for a narrow window of 3 days surrounding the announcement and for a wider window of 41 days surrounding the announcement. The $\mathrm{CAR}_{-1,+1}$ percentages ranged from 89 percent to -29 percent; the $\mathrm{CAR}_{20,+20}$ percentages ranged from 125 percent to -110 percent.

Announcement Effects by Industry. The differences in market reaction to a dividend initiation could be related to the company's industry. Industry is often associated with a company's investment opportunities and thus might influence the market effects of a dividend announcement. To address this possibility, we segregated the sample by industry (grouped by Standard Industrial Classification, SIC); Table 3 shows the results for the 3-day and 41-day intervals for 16 industries. 


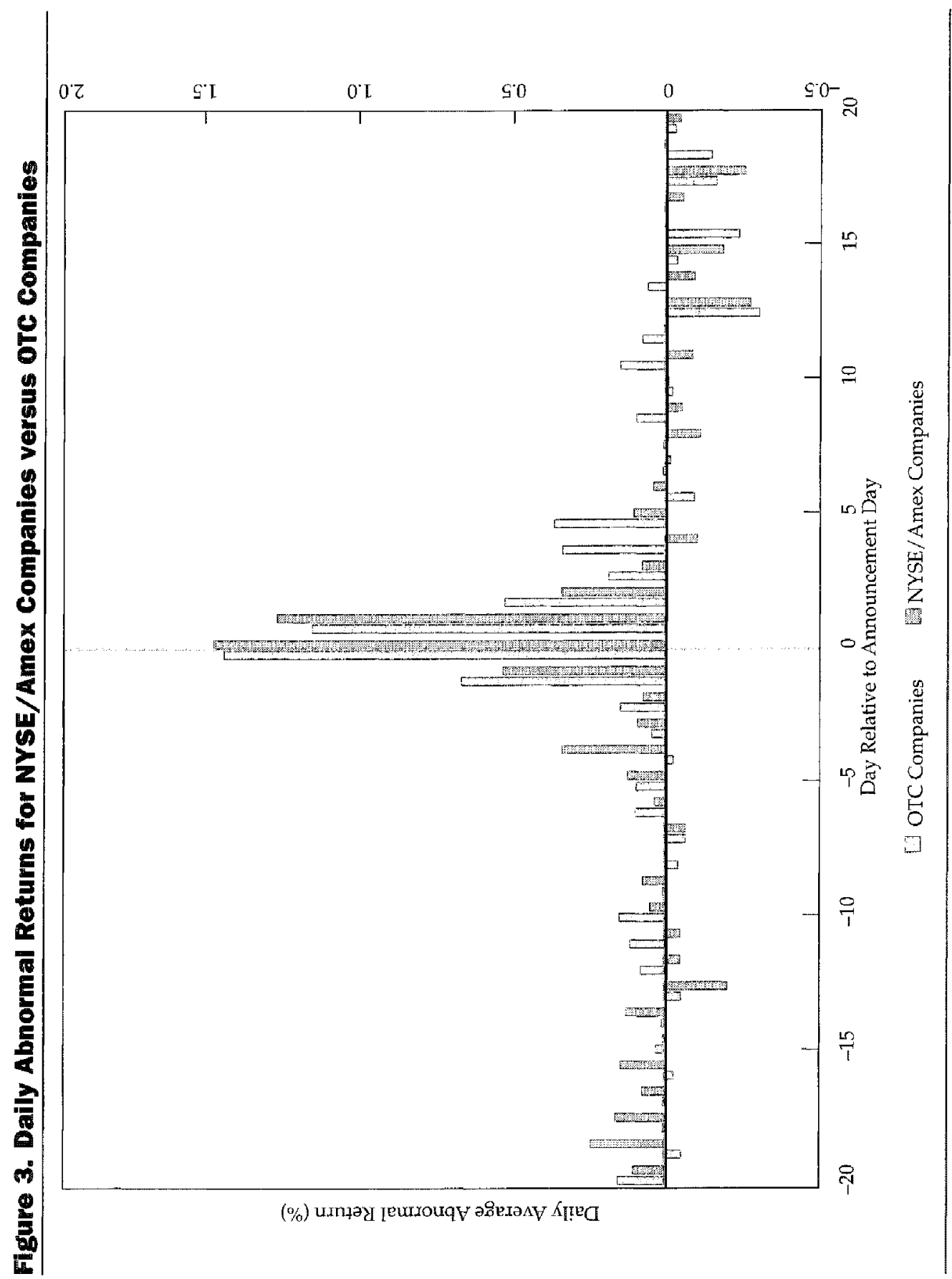


Table 2. Frequency Distributions of Dividend Announcement Effects

\begin{tabular}{ccc}
\hline & CAR $_{-1,+1}$ & CAR $_{20,+20}$ \\
\hline CAR $>0.50$ & 1 & 24 \\
$0.40<\mathrm{CAR} \leq 0.50$ & 2 & 31 \\
$0.30<\mathrm{CAR} \leq 0.40$ & 10 & 52 \\
$0.20<\mathrm{CAR} \leq 0.30$ & 27 & 113 \\
$0.10<\mathrm{CAR} \leq 0.20$ & 92 & 171 \\
$0 \leq \mathrm{CAR} \leq 0.10$ & 564 & 234 \\
$-0.10 \leq \mathrm{CAR}<0$ & 365 & 214 \\
$-0.20 \leq \mathrm{CAR}<-0.10$ & 14 & 121 \\
$-0.30 \leq \mathrm{CAR}<-0.20$ & 2 & 70 \\
$-0.40 \leq \mathrm{CAR}<-0.30$ & 0 & 31 \\
$-0.50 \leq \mathrm{CAR}<-0.40$ & 0 & 9 \\
CAR $<-0.50$ & 0 & 7 \\
Total & 1,077 & 1,077 \\
\hline
\end{tabular}

Note: $\mathrm{CAR}_{1,+1}$ is the cumulative abnormal return from Day -1 to $\mathrm{Day}+1$, and $\mathrm{CAR}_{-20+20}$ is the cumulative abnormal return during the 41 trading days around the dividend announcement

In general, we found that the announcement effects do not depend on the specific industry. Only two industries (lumber/wood products/furniture and wholesale goods) have 3-day announcement returns that differ significantly from the population mean, and only two industries (agriculture/mining and motor vehicles) have 41-day announcement effects that differ from the population mean. No industry-level 3-day effect is less than zero, although the agriculture/mining industry has a negative 41-day announcement effect.

Types of Initial Dividends. Brickley (1983) suggests that specially designated dividend (SDD) announcements, such as year-end dividends or extra, special, or final dividends, have different announcement effects from those of regular, unlabeled dividend announcements. This argument is based on the hypothesis that dividend changes convey information. Because most companies that increase their regular quarterly dividends do so only if confident of maintaining future dividends at the increased level, a regular dividend increase can be considered a positive market signal about future cash flows. Because SDDs do not imply permanence, they may impart less information to the market about expected future earnings than regular dividends import.

Brickley's results support the notion that management uses the labeling of dividends to convey information to the market about future dividends and earnings. He found that, as a group, companies with regular dividend increases have statistically larger earnings changes in the fiscal year following the dividend announcement than companies declaring SDDs.

Jayaraman and Shastri (1988) proposed that the positive market response 
to SDDs may result from wealth transfers from bondholders. Their tests found no significant impact on the bonds of companies announcing these dividends, however, from which they concluded that SDDs are positive signals to the market. The authors also found that the magnitude of the signal diminishes with the number of SDDs announced by a given company.

The effects of dividend-initiation announcements by type of dividend are presented in Table 4 . Of the entire sample, 448 observations did not have information in the CRSP files on the type of the initial dividend. Of the types specified, a quarterly dividend initiation, with 369 observations, was the most popular. The sample contained 103 SDDs, with 19 labeled as year-end or final and 84 identified as extra or special.

Unlike Brickley, we found no significant differences in the effects of initial

Table 3. Dividend Announcement Effects by Industry

\begin{tabular}{|c|c|c|c|c|}
\hline Industry & SIC Group & $\begin{array}{l}\text { Number of } \\
\text { Announce- } \\
\text { ments }\end{array}$ & $\mathrm{CAR}_{1,+1}$ & $\mathrm{CAR}_{-20,20}$ \\
\hline Agriculture/mining & $0100-0900,1000-1299,1400$ & 20 & 2.71 & $-3.53^{*}$ \\
\hline $\begin{array}{l}\text { Oil/gas/utilities/ } \\
\text { communications }\end{array}$ & $\begin{array}{l}1300-1399,2901-2999,4801- \\
4999\end{array}$ & 88 & 2.00 & 3.11 \\
\hline Construction & $500-1700$ & 23 & 2.39 & -0.29 \\
\hline Food and kindred products & 2000 & 34 & 3.84 & 10.90 \\
\hline Textiles/apparel & $2200-2300$ & 24 & 2.29 & 7.60 \\
\hline $\begin{array}{l}\text { Lumber/wood products/ } \\
\text { furniture }\end{array}$ & $2400-2500$ & 23 & $0.58^{*}$ & 8.07 \\
\hline Paper/printing/publishing & $2600-2700$ & 28 & 5.80 & 0.55 \\
\hline Chemicals/drugs & 2800 & 40 & 2.40 & 0.60 \\
\hline $\begin{array}{l}\text { Rubber/leather/stone } \\
\text { products }\end{array}$ & $3000-3200$ & 25 & 2.93 & 0.82 \\
\hline Metal/machine products & $3300-3500$ & 123 & 3.10 & 3.59 \\
\hline $\begin{array}{l}\text { Electrical equipment } \\
\text { Motor vehicles/parts/ } \\
\text { instruments/ } \\
\text { miscellaneous }\end{array}$ & 3600 & 88 & 4.40 & 5.38 \\
\hline manufacturing & $3700-3900$ & 102 & 3.77 & $9.71^{*}$ \\
\hline Transportation/pipeline & $4000-4700$ & 32 & 4.21 & 5.58 \\
\hline $\begin{array}{l}\text { Wholesale (durables and } \\
\text { nondurables) }\end{array}$ & $5000-5100$ & 48 & $5.58^{* *}$ & 5.66 \\
\hline Retail & $5200-5900$ & 103 & 3.67 & 3.36 \\
\hline Services & $7000-8900$ & 134 & 3.28 & 4.43 \\
\hline Entire sample & & 935 & 3.41 & 4.59 \\
\hline
\end{tabular}

Note: Table includes all companies with SIC codes listed on CRSP; missing or zero SIC codes were deleted.

${ }^{* \star}$ Significantly different from the population mean minus the observations in that SIC at the 5 percent level. 


\section{Table 4. Dividend-Initiation Announcement Effects by Type of Announcement}

\begin{tabular}{lccccc}
\hline & & \multicolumn{4}{c}{ Intervals } \\
\cline { 3 - 6 } Type of Announcement & Sample Size & CAR $_{-1,0}$ & CAR $_{-1,+1}$ & CAR $_{-20,+20}$ & CAR $_{-5,+5}$ \\
\hline Frequency unspecified & 448 & 2.24 & 3.47 & 5.48 & 4.90 \\
Quarterly & 369 & 1.90 & 3.04 & 4.51 & 4.53 \\
Semiannual & 97 & 1.31 & 2.60 & 2.36 & 4.17 \\
Annual & 60 & 1.35 & 2.36 & 3.55 & 3.34 \\
Year-end, final & 19 & 3.79 & 4.55 & 3.86 & 5.18 \\
Extra, special & 84 & 1.72 & 3.47 & 2.57 & 4.48 \\
\hline
\end{tabular}

dividend announcements based on the type of initial dividend. Based on our findings, specially designated initial dividends convey the same level of information to market participants as quarterly or other dividends. Note, however, that Brickley did not examine initial dividends.

Common Factors in Dividend Initiations. Table 2 showed that not all dividend initiations are greeted with enthusiasm by the market, which is not surprising considering that companies may initiate dividends for various reasons. Finance theory suggests that some companies may use the dividend initiation as a signal to investors of higher future earnings; other companies may initiate dividends based on an erosion of the company's investment opportunity set. These two scenarios have different implications for potential investors and suggest that different reasons for companies initiating dividends may rise from different financial characteristics of companies. Investors may be particularly interested in the financial characteristics of companies that initiate a dividend and have a large positive market response associated with the dividend decision.

One way to distinguish among the different motives for initiating dividends is through cluster analysis. Cluster analysis is used to form groups of similar characteristics. An advantage of cluster analysis in this context over such approaches as regression analysis is that cluster analysis does not require a linear mapping of company characteristics onto the clusters. In applying cluster analysis, the data are first standardized to zero mean and unit variance. Homogeneous groups are formed by minimizing the sum of the squared distances between centroids of each group. ${ }^{3}$

${ }^{3}$ The number of clusters that result from applying the clustering algorithm depends on the choice of parameters. We used the FASTCLUS procedure from the SAS Institute, with the maximum number of clusters set at 10 , the maximum iterations set at 30 , and clusters with fewer than five members deleted. For details on cluster analysis, see the SAS User's Guide: Statistics and Anderson (1973). 
In our study, we separated clusters of dividend-initiating companies on the basis of financial and market characteristics and on the basis of market response to the dividend announcement so that within-group differences would be relatively small compared with among-group differences. Thus, companies within a cluster are relatively homogeneous and companies in different clusters are relatively heterogeneous, at least with respect to the clustering variables. The appendix details the financial dimensions captured by the financial variables we used in the cluster analysis. The table in the appendix spells out the acronyms and contains the definitions of the variables. We selected these variables because they are dimensions commonly used to describe the state of a company in financial analysis and because prior empirical or theoretical studies have reported them to be associated with the dividend decision.

The variables represent eight dimensions of a company: liquidity, valuation, investment opportunities, size, profitability, leverage, growth, and activity (asset utilization). The measures of liquidity, profitability, leverage, and activity are those typically used in financial analyses to evaluate a company and are similar to those reported by most investment and credit services. Variables representing valuation, investment opportunities, and growth are based on measures suggested by Smith and Watts (1992), among others, as underlying managerial decisions. Size is included as a control variable. Size has been shown to proxy for several concepts, including access to capital markets and the degree of information known about the company.

The assignment of these variables to particular categories should not be thought of as absolute. The variable CBDMV (book value of equity divided by market value of equity), for example, could be considered a measure of either valuation or investment opportunities. The variable EV (market value of equity divided by market value of the company) is a leverage ratio as much as it is a measure of valuation. The categorization presented here is merely designed to facilitate interpretation of the analyses.

Exhibit 1 summarizes the distinguishing features of the clusters and the market response to each cluster's announcement of dividend initiation. Keep in mind that the interpretation of clusters is not always straightforward. Companies in Cluster 1 and Cluster 3 have low profitability, low cash flows, and low valuation measures. These companies (especially those in Cluster 1) use financial leverage to a greater extent than do companies in Cluster 2 and Cluster 4. Cluster 1 companies are also characterized by higher long-term investment than companies in Clusters 2 and 4, whereas the latter clusters' companies have higher profitability and cash flow and higher relative valuation (higher equityto-value measures and lower book-to-market ratios). 


\section{Exhibit 1. Summary of Distinguishing Cluster Characteristics}

Cluster 1 These companies had the second highest dividend-announcement effects; the effects were significantly larger than those in Clusters 2 or 4. Profitability and cash flow measures were consistently lower for companies in Cluster 1 than for companies in Clusters 2 or 4 ; leverage was consistently higher than in Clusters 2 and 4; market-to-book measures were lower. No consistent differences existed between Cluster 1 and Clusters 2 and 4 in liquidity, growth, or activity measures. Cluster 1 companies were among the highest in long-term investment.

Cluster 2 This group of companies had the lowest mean dividend-announcement effects. The equity-to-value ratios (EVs) of companies in this group were the second highest, and their book-to market ratios were the lowest. These companies were among the smallest in the study, and their profit and cash flow measures were among the highest. They also had the lowest debt ratios.

Cluster 3 These companies had the highest, at 5.6 percent, dividend-announcement effects. The companies in this group resembled the companies in Cluster 1 in that their profitability and cash flow ratios were low and their leverage measures were significantly above those in Clusters 2 and 4 . They also shared relatively lower market valuations; that is, their EVs were low and their book-to-market ratios were high. They had the greatest level of sales relative to assets. They also exhibited the lowest liquidity and lowest growth rates.

Cluster 4 These companies had the next-to-lowest mean dividend-announcement effects and the lowest median announcement effects. Only 28 companies fell into this cluster. Similarly to those in Cluster 2, the companies in Cluster 4 had high profitability and cash flow measures and modest leverage. Companies in this cluster were the second largest in terms of total assets. Their pattern of capital expenditures relative to total assets was consistent with companies without investment opportunities. Their EVs were high and their market-to-book ratios were low.

The results of the cluster analysis indicate that the market response to a dividend initiation is associated with the announcing company's financial characteristics. The mean and median values for the financial and market variables, identified by their acronyms, are shown in Table 5 , together with the market response during the 3 -day period surrounding the announcement and the market response during the 20-day period leading up to the announcement. Of particular interest to investors are the results for Cluster 1 and Cluster 3, which contain the companies with the largest announcement effects. The mean three-day excess returns for companies in Clusters 1 and 3 were 4 percent and 5.6 percent, respectively. The announcement effects for Cluster 2 and Cluster 4 were less than one-half the size of the effects for Clusters 1 and 3. Furthermore, the three-day excess return for Cluster 3 (5.6 
percent) is significantly larger than the excess return for Clusters 2 and 4 at the 1 percent level of significance, and the three-day excess return for Cluster 1 (4.0 percent) is significantly larger, at the 5 percent level of significance, than the excess return for Cluster 2. Thus, investors who are searching among non-dividend-paying stocks for likely candidates to initiate cash dividends might be well advised to focus on companies with the financial characteristics observed in Cluster 1 and Cluster 3.

One interpretation of the cluster descriptions given in Exhibit 1 and the results shown in Table 5 is that Cluster 1 and Cluster 3 contain undervalued companies that are signaling bright future prospects with their initial dividends whereas Cluster 2 and Cluster 4 contain companies with high profitability and cash flows but without substantial prospects for capital investment. Thus, the dividend decision for companies in Clusters 2 and 4 may signal to investors a maturation or reduction in future growth prospects.

Table 5. Mean and Median Values of Financial and Market Variables by Cluster

\begin{tabular}{lcccc}
\hline & \multicolumn{4}{c}{ Mean (Median) Values } \\
\cline { 2 - 5 } Variable & $\begin{array}{c}\text { Cluster 1 } \\
(N=67)\end{array}$ & $\begin{array}{c}\text { Cluster } 2 \\
(N=225)\end{array}$ & $\begin{array}{c}\text { Cluster } 3 \\
(N=221)\end{array}$ & $\begin{array}{c}\text { Cluster 4 } \\
(N=28)\end{array}$ \\
\hline CDTCA & $0.291(0.233)$ & $0.297(0.260)$ & $0.124(0.082)$ & $0.426(0.433)$ \\
EV & $0.245(0.226)$ & $0.679(0.670)$ & $0.340(0.349)$ & $0.687(0.688)$ \\
IOS & $6.296(4.600)$ & $1.320(1.198)$ & $4.517(3.736)$ & $1.501(1.111)$ \\
NPETA & $0.629(0.632)$ & $0.287(0.238)$ & $0.260(0.231)$ & $0.645(0.691)$ \\
CEDTA & $0.156(0.119)$ & $0.087(0.062)$ & $0.054(0.042)$ & $0.212(0.187)$ \\
NPDD & $17.338(10.384)$ & $8.035(7.436)$ & $7.787(7.291)$ & $13.163(9.703)$ \\
TA & $4.702(4.423)$ & $3.417(3.335)$ & $3.416(3.329)$ & $3.943(4.115)$ \\
NIDTA & $0.041(0.034)$ & $0.109(0.102)$ & $0.054(0.054)$ & $0.135(0.114)$ \\
NIDSA & $0.054(0.046)$ & $0.084(0.075)$ & $0.028(0.029)$ & $0.332(0.328)$ \\
CFDSA & $0.148(0.106)$ & $0.185(0.159)$ & $0.064(0.062)$ & $0.754(0.688)$ \\
LTDMVE & $2.863(2.125)$ & $0.187(0.103)$ & $0.823(0.574)$ & $0.228(0.150)$ \\
LTDTE & $2.029(1.720)$ & $0.294(0.170)$ & $0.427(0.372)$ & $0.297(0.236)$ \\
CBDMV & $1.706(1.206)$ & $0.746(0.650)$ & $2.074(1.874)$ & $0.936(0.542)$ \\
AGROW & $0.504(0.346)$ & $0.668(0.453)$ & $0.205(0.170)$ & $0.815(0.509)$ \\
SADTA & $1.023(0.874)$ & $1.434(1.355)$ & $2.213(1.913)$ & $0.413(0.375)$ \\
CAR_20,-2 & $0.062(0.033)$ & $0.001(-0.011)$ & $0.022(0.016)$ & $-0.041(-0.024)$ \\
CAR_1,+1 & $0.040(0.021)$ & $0.018(0.011)$ & $0.056(0.034)$ & $0.019(0.003)$ \\
\hline
\end{tabular}

Note: Companies in the cluster analysis included all companies in Standard and Poor's Corporation's Compustat annual industrial or research files with available data on the cluster variables. 


\section{Financial Characteristics of the Dividend-Initiating Company}

We have demonstrated that the average market reaction to the announcement of an initial dividend is substantial. In all cited studies, however, roughly one-third of the market price reactions are substantially negative. These nonpositive responses are not easily explained by existing dividend theories.

The lack of a homogeneous response to announcements of initial dividends suggests that the market may be able to anticipate announcements to some extent. One likely basis for anticipation of an initial dividend by the market is the existence of a discernible profile or set of company characteristics associated with the decision to begin paying dividends. The market's reaction to an initial dividend, then, would depend on differences in timing and magnitude between the anticipated dividend and its announcement and the actual dividend and its announcement. The dividend announcement and the profile would serve as corroborative evidence of the company's true status. Dividends initiated outside the profile might not be viewed favorably by stockholders.

Existing models of the firm predict that changes in a company's profile should precede an initial dividend. In life-cycle models, for example, a company in the development and growth stages has growth prospects but limited access to the capital markets. If the company is to exploit its investment opportunities, its resources are too scarce to permit internally generated cash to be paid out to shareholders. Only in later, more mature stages does the company have the necessary internal cash flows, liquidity, and access to capital markets to declare a dividend. Thus, changes in the company's financial characteristics, particularly those associated with maturing investment and financing opportunities, should be visible before the initiation of dividend payments.

Similarly, in models that link the dividend decision generally to management's expectations of future operating cash flows, managers declare a dividend when they expect future cash flows to be high enough and stable enough to support the payout. If the conditions that changed management's expectations of future cash flows also alter the company's reported financial characteristics, then such changes should be observable before the initiation of dividend payments.

In the following analysis, the financial characteristics of dividend-initiating companies are examined over time to determine whether some observable development in a company led to its decision to begin cash payouts to shareholders. The investigation is restricted to company characteristics of the type commonly used in financial analysis and excludes characteristics that are exogenous (such as the number of institutions investing in the company) and those that reflect the personal preferences of the managers (specifically, the 
insider ownership structure or the compensation of officers and directors). Univariate and multivariate analyses are applied to profile the dividend-initiating company. The analysis also examines differences between those dividend initiations greeted favorably by the market and those that receive unfavorable reactions.

Prior Descriptions of Dividend-Initiating Companies. For most research into financial decision making, the research turns early to empirical studies of possible determinants of cross-sectional differences in the policy being examined. Titman and Wessels (1988), for example, examined how certain attributes of the firm influence the choice of capital structure.

For dividend policy, however, especially dividend initiations, such research is scant. When empirical evidence is presented, it usually relates a specific subset of company characteristics to the dividend decision in order to decipher the nature of the information revealed by changes in dividends. In their extensive reviews of the dividend literature, neither Ang (1987) nor Allen and Michaely (1994) specifically addressed cross-sectional determinants of dividend policy.

In recent studies, the choice of variables has depended on the particular theory being tested. Earnings and variables believed related to the level, growth, and variability of future earnings and cash flows usually appear in studies motivated by an asymmetric information approach to dividend policy. In these information-based models of the firm, an increase in dividends indicates a company of higher-than-average quality with superior investment opportunities and growth.

Agency models of dividend behavior are somewhat broader than information-signaling models in their implications for a profile of the dividend-initiating company. Jensen (1986) argues that dividends are appropriate when the company begins to experience significant conflicts of interest between stockholders and managers. That is, companies with internally generated cash flows in excess of investment needs should distribute those funds to the market through dividends, stock buy-backs, and acquisitions. Life-cycle models also relate dividends to changes in earnings. In these models, dividend initiation becomes appropriate when the level and stability of the company's internally generated funds increase without an increase in growth opportunities or when the company's demand for internal funds decreases through either improved access to external funding or a decline in investment opportunities.

Overall, the evidence linking dividend changes to future changes in earnings is weak. Similarly, the results of empirical examinations of agency theoretic mod- 
els of dividend payments provide weak support at best (Allen and Michaely 1994). ${ }^{4}$

A study by Wansley and Lane (1987) (hereafter, WL) is the only explicit attempt to derive a profile of the dividend-initiating company. ${ }^{5} \mathrm{WL}$ examined a sample of such companies by comparing the values of a set of variables in the announcement year to those values in each of the four preceding years. The results suggest that in the years leading to the decision, companies that initiate dividends experience increasing size and profitability and decreasing leverage and market valuation relative to earnings. Two-thirds of the WL sample showed a discernible change in their announcement-year profile compared with the profile of two years prior to the announcement.

WL considered their results consistent with informational signaling, in the sense that the dividend initiation is treated as a reward to reinforce the signal of improvements in the company's financial condition. WL also expressed dismay at their misclassification rate. The statistical significance of the average market response to an initial dividend announcement indicates that a substantial unanticipated element is present, however, and that a sizable misclassification rate is to be expected from publicly available information.

\section{Analysis}

Our base sample was those companies selected for the event study. To generate a profile of the dividend-initiating company, however, we needed additional information from the companies' financial statements; therefore, the sample was further restricted to those companies included in Standard and Poor's Corporation's Compustat data files for at least one year prior to the announcement. The variables are the same ones used in the cluster analysis and essentially the same as those used by WL. Of the companies for which threeday cumulative prediction errors $\left(\mathrm{CAR}_{-1,+1}\right)$ were calculated, 862 had at least some financial statement information on Compustat in the year preceding the announcement, 655 had some information for two years prior, and 541 had some information for three years prior.

Not all data items were available for each company in every year. Of the 862

\footnotetext{
${ }^{4}$ The lack of empirical support for any of the extant theories led Frankfurter and Lane (1992) to suggest that economic rationality will never be able to explain why companies pay dividends. They view the dividend decision as corporate behavior with roots that go back in history to the development of the modern corporation.

${ }^{5}$ In their attempt to differentiate between signaling theory and agency theory, Lipson, Maquieira, and Megginson (1995) created a profile underlying the initial dividend decision, but their profile relates to changes in the company after initiating dividends, not changes preceding initiation. Their results support a life-cycle model of dividends.
} 
companies with some information one year before announcement, only 370 had data available for all 26 variables. Similarly, of the 655 (541) companies with Compustat information two (three) years before the dividend announcement, only 335 (245) had complete information.

The objective of the analysis was to determine those company characteristics associated with the decision to initiate dividends. Similar to the analysis in WL, the characteristics of dividend-initiating companies were determined by comparing the characteristics of each company in the sample in the year of the initial dividend declaration with the company's characteristics in the three years prior to the declaration of the initial dividend. The results thus have implications for both why and when companies initiate dividends.

The base year (defined as Year $t-1$ ) is the first fiscal year prior to the announcement. The base year thus provides the financial statement information known about the company before the initial dividend. The analysis compares the values of the variables in that year with, first, the variables two years prior to announcement (Year $t-2)$ and, then, with the variables three years prior to the announcement (Year $t-3$ ). The profile of dividend-initiating companies is thus determined by the differences in the variables over time.

We conducted univariate $t$-tests by pairing each company in Year $t-1$ with itself in Years $t-2$ and $t-3$. Univariate tests identify those variables for which statistically significant differences between years occur in the means of the distributions. As noted previously, the sample size was greatly reduced by a requirement for information for every variable. By considering one variable at a time, the univariate tests, allowed us to use the greatest number of observations. The trade-off is that any interactions among the variables could not be recognized.

To capture the effects of such interactions, we also used logit analysis to construct the profile. The intent was to identify the most-significant differences occurring in the three years, so we used a stepwise logit procedure to select the subset of variables with the greatest ability to discriminate between the two groups (that is, between Years $t-1$ and $t-2$ and between Years $t-1$ and $t-3)$. The stepwise procedure assured that each estimate of the coefficients of all variables in the final models was significantly different from zero (chisquare statistic significant at the 10 percent level or better).

Logit analysis is one of several multivariate classification techniques. Unlike discriminant analysis, used by WL, logit assumes neither that the independent variables are distributed as multivariate normal nor that the two groups have equal covariance matrixes. For more information on either of these procedures, see Kennedy (1992, Chapter 15).

Because the market reacts negatively to most announcements of initial 
dividends, the profile of companies whose announcements of initial dividends are received favorably is likely to differ from that of companies whose announcements are received adversely. To determine whether differences in the sign of the market's reactions to announcements are associated with differences in profile, we conducted univariate $t$-tests within each year that compared the means when the $\mathrm{CAR}_{-1,+1}$ values were positive with the means when the $\mathrm{CAR}_{1,+1}$ values were negative. Finally, we repeated the logit analyses separately for samples of positive and negative $\mathrm{CAR}_{-1,+1}$ values.

\section{Results}

Table 6 presents the sample characteristics for each variable for each of the three years prior to dividend initiation. Table 6 also contains the results of the $t$-tests. As would be expected, companies in this sample are fairly small. The average market value of equity is $\$ 71.1$ million (median $\$ 14.8$ million), and the figure for average total assets is $\$ 111.4$ million (median $\$ 29.4$ million). The average size of these companies did not change appreciably during the three years.

In the year prior to the dividend, the companies in the sample show a significant increase in the proportion of current assets held as cash and marketable securities (CDTCA). No significant change is observed in the other liquidity measure, CURRENT.

Of the three valuation ratios, only the price-to-earnings ratio (acronym $\mathrm{PE}$ ) shows a statistically significant change, a decrease, in the mean for Year $t-1$ compared with Year $t-2$ and Year $t-3$. The absence of any trend in the other two valuation ratios suggests that the effect on $P E$ stems from increases in earnings. This conjecture is supported by all of the profitability ratios with the exception of GPM, the gross profit margin. The four profitability ratios show significant increases in Year $t-1$ compared with Year $t-2$ and (with the exception of NIDSA, the net profit margin) with Year $t-3$. The results for the valuation and profitability variables together indicate that, on average, the dividend-initiating company is characterized by increasing profitability without a corresponding increase in stock price in the years before the dividend announcement.

The variable IOS (investment opportunity schedule) exhibits a significantly smaller mean in Year $t-1$ than in Years $t-2$ or $t-3$. Confounding the interpretation of this result, however, the median for IOS increases slightly over the period. Consistent with the observed increase in profitability, the IOS variables measuring research and development expenses (RADDS) and capital expenditures (CEDTA) show a significant decline in Year $t-1$ relative to Year $t-3$, and the RADDS variable shows a significant decline relative to Year $t-2$.

Also consistent with the increased profitability is a decrease in the use of 


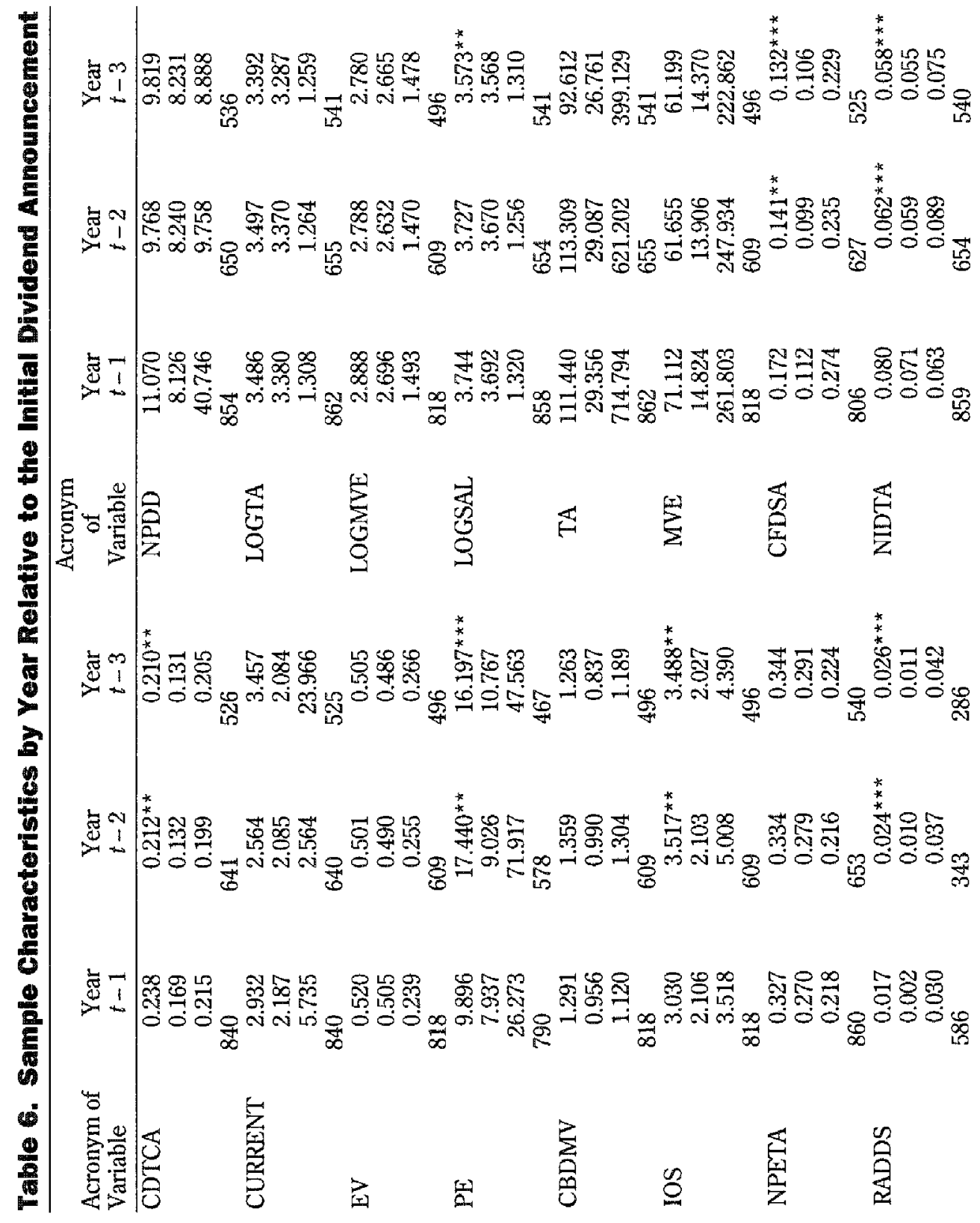




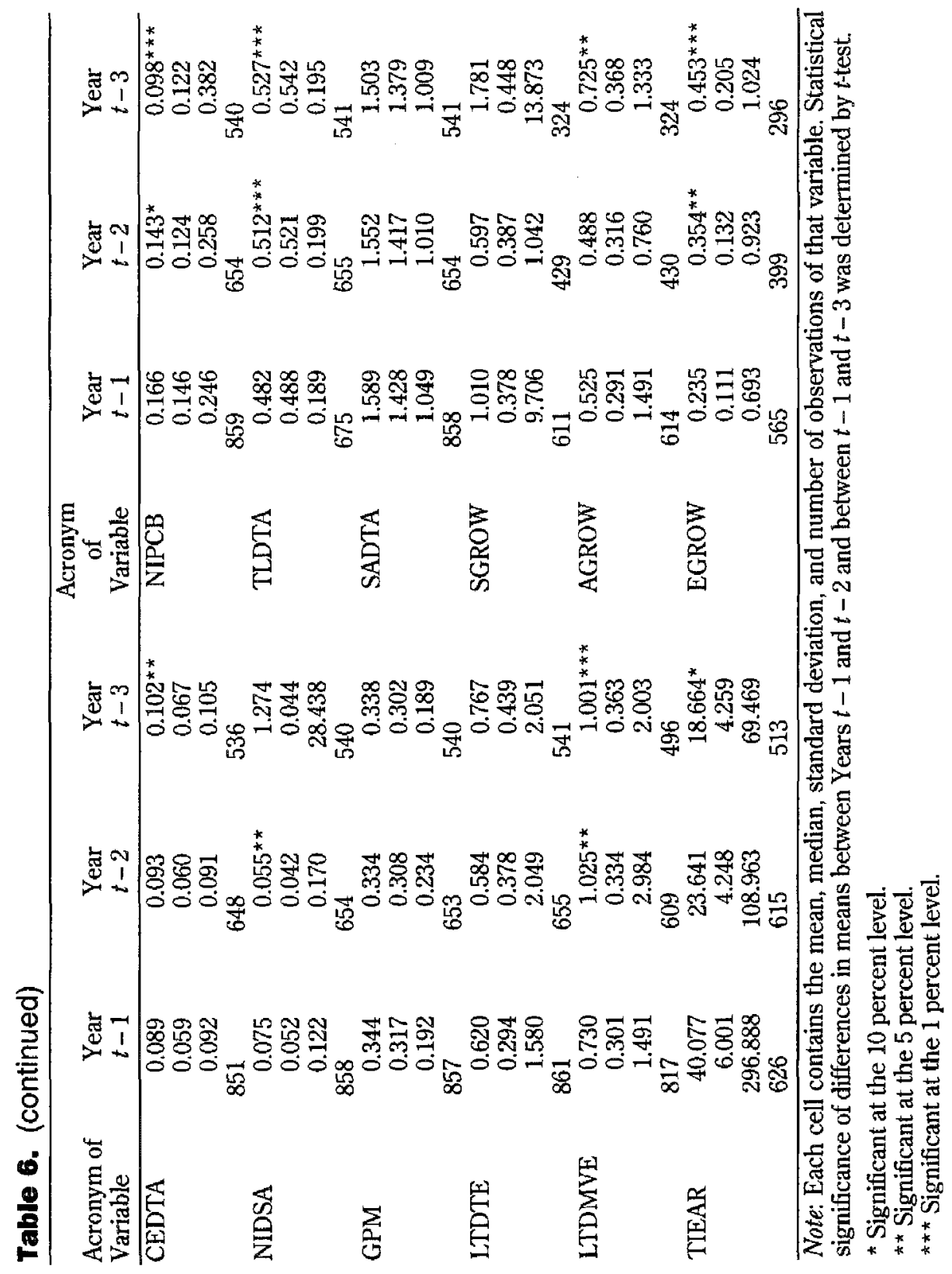


debt financing, indicated by three of the four leverage variables: book value of long-term debt to market value of equity (LTDMVE), total liabilities to total assets (TLDTA), and operating income minus depreciation to interest expense (TIEAR). The means of the variable measuring activity, sales to total assets (SADTA), are not significantly different from year to year.

The results provide weak evidence of declining rates of growth for these companies. The medians of all three growth variables also decline across time, which is a qualitative indicator of declining growth rates. Differences in the means are statistically significant for the rate of growth in number of employees (EGROW) when comparing Year $t-1$ with both Year $t-2$ and Year $t-3$ and for growth in assets (AGROW) for Year $t-1$ versus Year $t-3$.

The overall profile based on the univariate tests is of a company realizing an increase in profitability concurrent with a decline in growth and investment opportunities. The company's stock price, however, has not changed. This profile is consistent with both the life-cycle view of the firm and the view of dividend initiations as information signaling (the signal being that management expects the higher earnings to be permanent).

Table 7 and Table 8 report the results for the logit analyses comparing Year $t-1$ with, respectively, Year $t-2$ and Year $t-3$. Several of the variables with statistically significant differences in the univariate tests do not enter the logit models, most likely because of interactions between those variables and ones that do appear in the logit results. The multivariate results are nonetheless generally consistent with those of the univariate tests. The $p$-values shown in Tables 7 and 8 are the probability of observing a greater chi-square statistic and are the smallest level of significance that would lead to rejecting the hypothesis that a coefficient is equal to zero.

No liquidity variable was selected for either model. Differences in company size, insignificant in the univariate comparisons, entered both models-in terms of level (log of total assets [LOGTA] for Year $t-2$ and $\log$ of sales [LOGSAL] for Year $t-3$ ) and rate of change (AGROW). Company size is probably capturing the effects of several of the variables that exhibited significant changes during the period but did not enter the model. The signs of the coefficients for LOGTA, LOGSAL, and AGROW indicate that the companies were growing at a decreasing rate as they approached the dividend decision. Increases in profitability, denoted by the positive coefficient of net income to total assets (NIDTA) and net income to sales (NIDSA), also appear in both models.

Declining investment opportunities are observed in the negative coefficients on IOS in Tables 7 and 8. Similarly, declining valuation (relative to profitability) is noted in the negative sign on the coefficient of PE in Table 8.

Approximately two-thirds of the observations are correctly classified when 
Table 7. Logit Comparison of Financial Characteristics at Year $t-1$ with Characteristics at Year $\boldsymbol{t}-2$ : Selected Variables

A. Variables selected

$\begin{array}{lccc}\text { Variable } & \begin{array}{c}\text { Maximum Likelihood } \\ \text { Parameter Estimate }\end{array} & \begin{array}{c}\text { Chi-Square } \\ \text { Intercept }\end{array} & \begin{array}{c}p \text {-Value of } \\ \text { Chi-Square }\end{array} \\ \text { IOS } & -1.0144 & 7.4312 & 0.0064 \\ \text { LOGTA } & -0.0561 & 3.8263 & 0.0505 \\ \text { NIDTA } & 0.2390 & 10.0489 & 0.0015 \\ \text { AGROW } & 9.4224 & 19.2188 & 0.0001 \\ & -0.6538 & 13.8042 & 0.0002\end{array}$

B. Classification table

Observed

$t-1$

$t-2$

Totals

Correct: $(195+194) / 310=0.638$

\begin{tabular}{ccc}
\multicolumn{2}{c}{ Predicted } & \\
\cline { 1 - 2 }$t-1$ & $t-2$ & Totals \\
\hline 195 & 110 & 305 \\
$\frac{111}{306}$ & $\underline{194}$ & $\underline{305}$ \\
& $\underline{304}$ &
\end{tabular}

Sensitivity: $195 / 305=0.639$

Specificity: $194 / 305=0.636$

C. Test for goodness of fit

$$
\begin{aligned}
& -2 \log \text { likelihood }=50.720 \\
& (p \text {-value }=0.001) \\
& \text { Pseudo- } R^{2}=0.060
\end{aligned}
$$

$\overline{\text { Note: Variables selected with a stepwise procedure. The level of statistical significance of each }}$ chi-square statistic is given by the associated $p$-value.

comparing Year $t-1$ with Year $t-2$ (63.8 percent) and with Year $t-3(67.6$ percent). Similar accuracy is observed in the classification of the observations from Year $t-1$ (the sensitivity of the model) and from Years $t-2$ and $t-3$ (the specificity of the model).

Univariate Analysis of Positive versus Negative Reactions. For this analysis, within each year, we separated the sample into those companies with a value of $\mathrm{CAR}_{1,+1}$ greater than or equal to zero and those with a value less than zero. We then conducted univariate $t$-tests to determine whether the sign of $\mathrm{CAR}_{-1,+1}$ was associated with differences in the mean value of each variable. The results of these tests are shown in Table 9.

Of the 26 variables, 9 show differences in at least one year. The three valuation ratios $(\mathrm{EV}, \mathrm{PE}$, and $\mathrm{CBDMV}$ ) indicate that higher relative stock prices are associated with companies eventually receiving negative reactions to their 
Table 8. Logit Comparison of Financial Characteristics at $t-1$ with Characteristics at Year $\mathbf{t}-3$ : Selected Variables

A. Variables selected

\begin{tabular}{lccc} 
Variable & $\begin{array}{c}\text { Maximum Likelihood } \\
\text { Parameter Estimate }\end{array}$ & Chi-Square & $\begin{array}{c}p \text {-Value of } \\
\text { Chi-Square }\end{array}$ \\
\hline Intercept & -0.6158 & 1.8840 & 0.1699 \\
PE & -0.0072 & 2.8636 & 0.0906 \\
IOS & -0.1786 & 20.9305 & 0.0001 \\
LOGSAL & 0.3722 & 16.0786 & 0.0001 \\
NIDSA & 8.7342 & 11.7950 & 0.0006 \\
AGROW & -1.4397 & 28.7563 & 0.0001
\end{tabular}

B. Classification table

$$
\begin{gathered}
\text { Observed } \\
t-1 \\
t-3 \\
\text { Totals }
\end{gathered}
$$

Correct: $(164+139) / 448=0.676$

\begin{tabular}{rrr}
\multicolumn{2}{c}{ Predicted } & \\
\cline { 1 - 2 }$t-1$ & $t-3$ & Totals \\
\hline 164 & 60 & 224 \\
$\frac{85}{249}$ & $\frac{139}{199}$ & $\frac{224}{448}$
\end{tabular}

Sensitivity: $164 / 224=0.732$

Specificity: $139 / 224=0.621$

C. Test for goodness of fit

$$
\begin{aligned}
& -2 \log \text { likelihood }=88.332 \\
& (p \text {-value }=0.001) \\
& \text { Pseudo- } R^{2}=0.142
\end{aligned}
$$

Note: Variables selected with a stepwise procedure. The level of statistical significance of each chi-square statistic is given by the associated $p$-value.

initial dividends. This same result is observed in IOS and explicitly in LOGMVE. There is also an association between higher earnings, as measured by three profitability measures (NIDTA, NIDSA, and GPM), and a negative market reaction. Finally, the variable SADTA has smaller values when linked to negative values of $\mathrm{CAR}_{-1,+1}$ than when linked to positive $\mathrm{CAR}_{-1,+1}$ values. These results parallel the descriptions of Cluster 2 and Cluster 4 , the two low-market-response clusters, in the previous section.

Two interpretations of these results are possible. The first is that companies earning relatively higher returns and receiving higher relative equity values should refrain from initiating dividends. The shareholders of these companies seem to react negatively to funds being paid out instead of reinvested. The results do not offer complete support, however, for this conclusion. The rest of the profile-specifically, the absence of significant differences in growth rates 
Table 9. Arithmetic Means of Variables by Year Relative to the Initial Dividend Announcement and Sign of the Three-Day CAR

\begin{tabular}{|c|c|c|c|c|}
\hline Acronym o & of Variable & Year $t-1$ & Year $t-2$ & Year $t-3$ \\
\hline$\overline{\mathrm{EV}}$ & $\geq 0$ & $0.502^{\star \star \star}$ & $0.480^{* \star *}$ & \\
\hline & $<0$ & 0.550 & 0.539 & \\
\hline $\mathrm{PE}$ & $\geq 0:$ & & & $12.690^{*}$ \\
\hline & $<0$ & & & 23.054 \\
\hline CBDMV & $\geq 0$ : & $1.354^{\star *}$ & $1.437^{\star \star}$ & \\
\hline & $<0$ : & 1.180 & 1.215 & \\
\hline IOS & $\geq 0$ : & $3.240^{\star *}$ & $3.759^{*}$ & \\
\hline & $<0$ & 2.660 & 3.070 & \\
\hline LOGMVE & $\geq 0$ : & & $2.698^{* *}$ & \\
\hline & $<0$ & & 2.954 & \\
\hline NIDTA & $\geq 0$ & $0.077^{\star \star}$ & & \\
\hline & $<0:$ & 0.086 & & \\
\hline NIDSA & $\geq 0$ & $0.069^{\star}$ & $0.042^{\star \star}$ & \\
\hline & $<0$ & 0.084 & 0.078 & \\
\hline GPM & $\geq 0$ : & $0.331^{* * *}$ & $0.313^{\star \star \star}$ & $0.324^{* *}$ \\
\hline & $<0$ & 0.368 & 0.373 & 0.365 \\
\hline SADTA & $\geq 0$ : & $1.647^{\star *}$ & $1.616^{\star \star}$ & $1.569^{* \star}$ \\
\hline & $<0$ & 1.487 & 1.436 & 1.379 \\
\hline
\end{tabular}

Note: Each cell contains, for that combination of variable and year, the mean for those observations with $\mathrm{CAR}_{1,+1}>0$, the mean for those with $\mathrm{CAR}_{1,+1}<0$, and an indicator of the statistical significance of the difference between the means. Only those variable/years with statistically significant differences (determined by $t$-test) in means are shown.

* Significant at the 10 percent level.

** Significant at the 5 percent level.

$\star \star \star$ Significant at the 1 percent level.

and in other measures of investment opportunities-does not indicate that these companies have superior opportunities for reinvestment of earnings.

The second interpretation is that the negative market response is the result of unfulfilled market expectations: The market anticipated a larger initial dividend from those companies earning higher returns and had already rewarded them with higher relative equity values, so the actual announcement was a disappointment.

Logit Analysis. To gain more insight into the possible differences among dividend-initiating companies, we separated the sample again into companies with a value of $\mathrm{CAR}_{1,+1}$ greater than or equal to zero and companies with a $\mathrm{CAR}_{1,+1}$ value less than zero. For each subsample, we applied the stepwise logit procedure to select the set of variables with the greatest ability to discriminate between Years $t-1$ and $t-2$ and between Years $t-1$ and $t-3$. The results of these tests are shown in Tables 10,11 , 
12 , and 13. (We also applied the stepwise logit procedure to classify companies by the sign of $\mathrm{CAR}_{-1,+1}$ using all three years of data. These results, not shown here, also showed that profitability, particularly in Year $t-1$, is the major discriminator between positive and negative market reactions.)

Positive market reactions. Results for the comparison of Year $t-1$ with Year $t-2$ for observations with $\mathrm{CAR}_{-1,+1}$ greater than or equal to zero are reported in Table 10 . The accuracy of the classification is slightly less than that of Table 7, which ignored the sign of $\mathrm{CAR}_{-1,+1}$. The model, consisting of three variables, is similar and indicates that increased size (LOGMVE), increased profitability (NIDTA), and decreased growth (EGROW) are associated with positive dividend-announcement effects. Notably absent is any measure of the investment opportunity schedule.

The logit model for Year $t-1$ versus Year $t-3$, shown in Table 11, selected different variables from the same groupings. Profitability is captured by CFDSA instead of NIDTA, and growth is measured by AGROW instead of EGROW, with the same signs as in Table 10 . These two variables are joined by a measure of

Table 10. Logit Comparison of Financial Characteristics at Year $t-1$ with Characteristics at Year $t-2$ : $\geq$ Zero

\begin{tabular}{lccc}
\hline A. Variables selected & Maximum Likelihood & & \\
Variable & Parameter Estimate & Chi-Square & $\begin{array}{c}p \text {-Value of } \\
\text { Chi-Square }\end{array}$ \\
\hline Intercept & -0.8361 & 9.9484 & 0.0016 \\
LOGMVE & 0.1640 & 4.5926 & 0.0321 \\
NIDTA & 9.2895 & 13.4257 & 0.0002 \\
EGROW & -0.6231 & 7.8350 & 0.0051
\end{tabular}

B. Classification table

Observed

$t-1$

$t-2$

Total

\begin{tabular}{crr}
\multicolumn{2}{c}{ Predicted } & Total \\
\hline \multicolumn{1}{c}{$t-1$} & \multicolumn{1}{c}{$t-2$} & 195 \\
120 & 75 & $\frac{195}{390}$ \\
$\frac{86}{206}$ & $\underline{109}$ &
\end{tabular}

Correct: $(120+109) / 390=0.587$

Sensitivity: $120 / 195=0.615$

Specificity: $109 / 195=0.559$

C. Test for goodness of fit

$$
\begin{aligned}
& -2 \log \text { likelihood }=24.606 \\
& (p \text {-value }=0.0001) \\
& \text { Pseudo- } R^{2}=0.046
\end{aligned}
$$

Note: Variables selected with a stepwise procedure. The level of statistical significance of each chi-square statistic is given by the associated $p$-value. 
Table 11. Logit Comparison of Financial Characteristics at Year $t-1$ with Characteristics at Year $t-3: \geq$ Zero

A. Variables selected

\begin{tabular}{lccc} 
Variable & $\begin{array}{c}\text { Maximum Likelihood } \\
\text { Parameter Estimate }\end{array}$ & $\begin{array}{c}\text { Chi-Square } \\
\text { Chilue of } \\
\text { Chi-Square }\end{array}$ \\
\hline Intercept & -0.0450 & 0.0076 & 0.9305 \\
IOS & -0.1852 & 14.5143 & 0.0001 \\
LOGSAL & 0.2707 & 5.5828 & 0.0103 \\
CFDSA & 2.1987 & 3.9556 & 0.0467 \\
AGROW & -1.6140 & 19.8758 & 0.0001
\end{tabular}

B. Classification table

Observed

$t-1$

$t-3$

Total

Predicted

\begin{tabular}{ccc}
\hline$t-1$ & $t-3$ & Total \\
\hline 110 & 37 & 147 \\
$\frac{58}{168}$ & $\frac{89}{126}$ & $\frac{147}{294}$
\end{tabular}

Correct: $(110+89) / 294=0.677$

Sensitivity: $110 / 147=0.748$

Specificity: $89 / 147=0.605$

C. Test for goodness of fit

$$
\begin{aligned}
& -2 \text { log likelihood }=52.032 \\
& (p \text {-value }=0.0001) \\
& \text { Pseudo- } R^{2}=0.128
\end{aligned}
$$

Note: $\overline{\text { Variables selected with a stepwise procedure. The level of statistical significance of each }}$ chi-square statistic is given by the associated $p$-value.

investment opportunities (IOS) and size (LOGSAL). The overall classification accuracy is essentially unchanged from that in Table 8 (all observations at $t-3$ ) and superior to that in Table $10\left(t-2\right.$ and nonnegative $\left.\mathrm{CAR}_{-1,+1}\right)$.

Negative market reactions. The model estimated by comparing Year $t-1$ with Year $t-2$ when the sample was restricted to those companies receiving a CAR ${ }_{-1,+1}$ less than zero is reported in Table 12 , and the model comparing Year $t-1$ with Year $t-3$ appears in Table 13. As in the previous logit models, a profitability measure (NIDTA) with a positive coefficient, indicating increases in profitability, has entered the model. A second profitability measure, CFDSA (net profit margin based on cash flow instead of net income), also appears with a positive coefficient. Consistent with the previous models, size (LOGTA) enters the model with a positive coefficient; a growth measure (AGROW) appears in the model with a negative coefficient.

Conclusions. All six logit analyses share three elements: 
Table 12. Logit Comparison of Financial Characteristics at Year $t-1$ with Characteristics at Year $t$ - 2: $<$ Zero

\begin{tabular}{lccc}
\hline A. Variables selected & $\begin{array}{c}\text { Maximum Likelihood } \\
\text { Parameter Estimate }\end{array}$ & Chi-Square & $\begin{array}{c}p \text {-Value of } \\
\text { Chi-Square }\end{array}$ \\
Variable & -1.8127 & 8.6905 & 0.0032 \\
\hline Intercept & 0.2829 & 4.5764 & 0.0324 \\
LOGTA & 1.4224 & 2.8644 & 0.0906 \\
CFDSA & 12.3923 & 12.4556 & 0.0004 \\
NIDTA & -0.9098 & 8.4742 & 0.0036 \\
AGROW & &
\end{tabular}

B. Classification table

Observed

$t-1$

$t-2$

Total

Correct: $(65+71) / 220=0.618$

\begin{tabular}{ccc}
\multicolumn{2}{c}{ Predicted } & \\
\hline$t-1$ & $t-2$ & Total \\
\hline 65 & 45 & 110 \\
$\frac{39}{104}$ & $\frac{71}{116}$ & $\underline{110}$ \\
& & 220
\end{tabular}

Sensitivity: $65 / 110=0.591$

Specificity: $71 / 110=0.645$

C. Test for goodness of fit

$-2 \log$ likelihood $=28.135$

( $p$-value $=0.0001$ )

Pseudo- $R^{2}=0.092$

Note: Variables selected with a stepwise procedure. The level of statistical significance of each chi-square statistic is given by the associated $p$-value.

- increasing profitability (measured by NIDSA, CFDSA, or NIDTA),

- decreasing growth rates (measured by EGROW or AGROW), and

- increasing size (LOGTA, LOGSAL, or LOGMVE).

These three elements are, therefore, the common thread underlying the initiation of dividends. Dividend-initiating companies report increased profitability but reduced rates of growth and investment opportunities and stable relative stock prices. This profile satisfies both the life-cycle and the information-signaling views of the firm.

The classification rates are not so high, however, as to indicate that this simple profile will accurately predict the year in which management will initiate dividends. Consequently, the market reaction to an announcement of an initial dividend probably reflects a substantial element of surprise.

The profile does not differ appreciably between those companies receiving a negative market reaction and those receiving a positive reaction to the 
Table 13. Logit Comparison of Financial Characteristics at Year $t-1$ with Characteristics at Year $t-3:<$ Zero

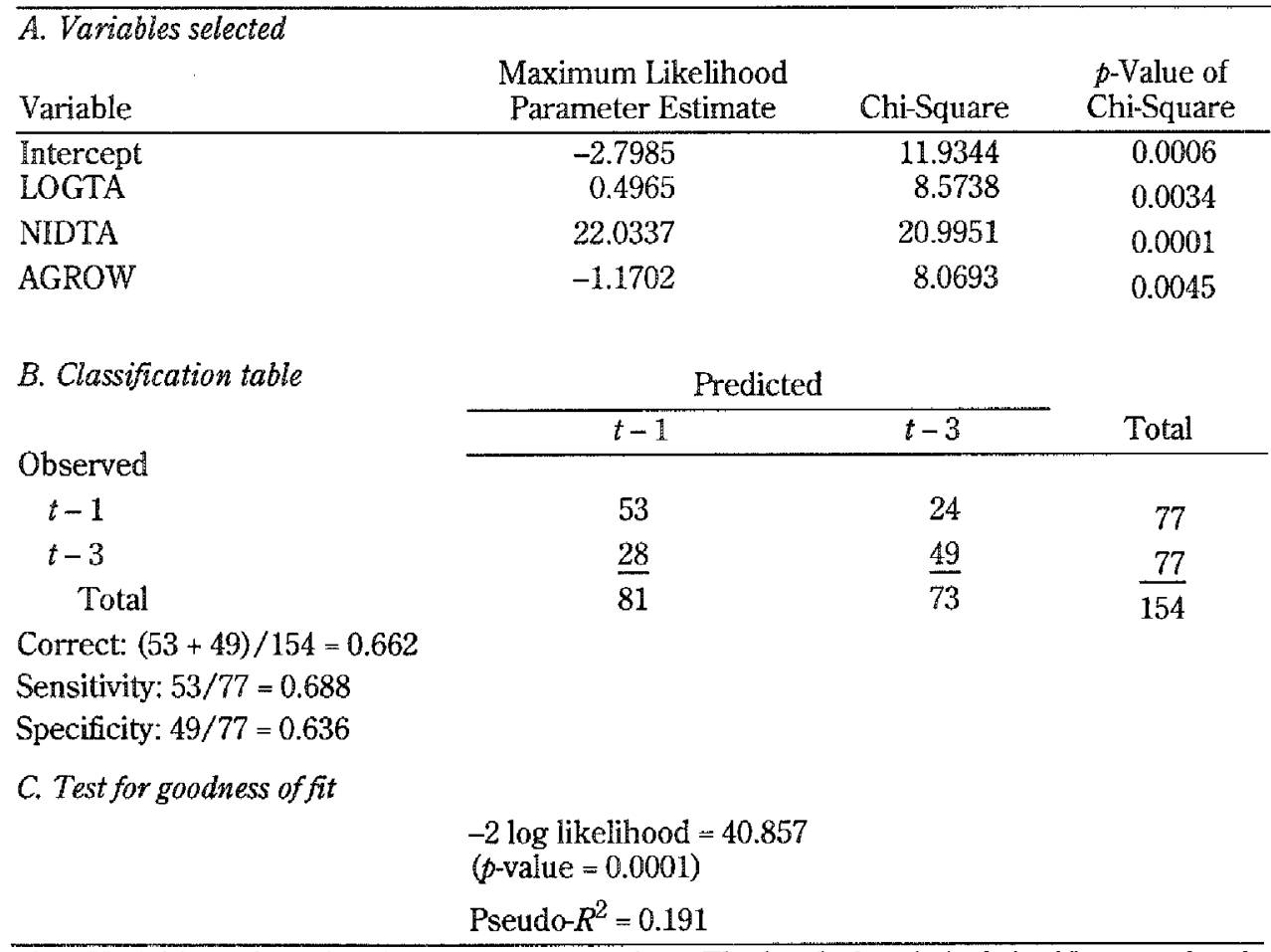

Note: Variables selected with a stepwise procedure. The level of statistical significance of each chi-square statistic is given by the associated $p$-value.

dividend announcement. Direct comparisons of the two groups reveal, however, that they are not homogeneous. A higher relative stock price (EV, PE, and CBDMV) and higher earnings (NIDTA, NIDSA, and GPM) are associated with a negative $C A R_{-1,+1}$. The absence of significant differences in growth rates and in other measures of investment opportunities does not suggest that these companies should have reinvested the funds instead of paying dividends at that time but, rather, that the market expected an even larger payout than was announced.

\section{Portfolio Construction Strategies}

The previous sections demonstrated two fundamental findings. First, there is an average excess return around the announcement date of an initial dividend on the order of 3 percent for NYSE/Amex and OTC companies but this return exhibits quite a bit of cross-sectional variation. Second, dividend-initiating 
companies exhibit accounting-based characteristics that change in the two years prior to the dividend announcement, and the changes for companies receiving positive excess returns around the dividend initiation announcement differ from the changes for companies receiving negative excess returns.

Although variable, the excess returns are statistically and economically significant, which suggests that a strategy of buying non-dividend-paying stocks on the dividend-announcement date and holding them for some length of time should yield excess portfolio returns. The implementation of this strategy, however, is not straightforward. The actual return realized by purchasing as soon as the announcement is made public will differ from the reported announcement-day return, and in the absence of inside information, an investor cannot realize the announcement-day return, which would entail purchasing the stock at the close on the day before the announcement. The Day +1 return might also be difficult to realize, because doing so would require purchasing the stock at the close on the announcement day. If the announcement were to occur after the exchange closed, the purchase would have to be made at the opening price on Day +1 , and any price appreciation from the close on the announcement day to the open on the next day would be forgone.

Another complication to realizing the announcement-day excess return is that the event study methodology that identified the 3 percent average excess return aggregated security returns in a way that is not realizable in trading time. Each of the announcement dates is considered to be the same date for the purpose of the test, and a hypothetical portfolio is formed "in event time." The average announcement-date portfolio return is thus the average of the returns earned by all of the individual dividend-initiating stocks on the individual announcement dates, not a return that a portfolio could earn on any particular date. A portfolio strategy of purchasing stocks on the announcement of an initial dividend and holding the stocks for, say, five days would result in a portfolio consisting of no stocks for many days and then one stock for several days. This portfolio would not be well diversified and would not be invested in the market at all for many days.

In summary, the primary problems in developing a portfolio construction strategy based on the announcement-day findings are, first, that the excess return occurs over a fairly short time period and is fairly infrequent, so few stocks fit the investment criteria at any point in time and the resulting portfolio will not be well diversified, and second, in the absence of inside information, predicting which companies will announce an initial dividend on a particular day is difficult to impossible. Thus, the excess return on the announcement day is largely unobtainable.

Given these issues, an obvious empirical question is whether any portfolio 
or trading strategies exist that can profitably make use of public information on dividend initiation. This section analyzes two portfolio selection techniques that may mitigate the problems: first, holding selected stocks that have just announced an initial dividend for some optimal length of time, and second, using the logit model developed in the last section to predict which stocks will eventually declare an initial dividend, buying a portfolio of those stocks before the announcement, and holding the stocks. For analyzing the possibly rewarding strategies, we examined the returns to three trading strategies:

- Strategy 1. Purchase a portfolio consisting of all stocks that have neither paid nor announced a dividend. Hold the stocks until one year after dividend initiation.

- Strategy 2. Purchase all stocks that have just announced a dividend initiation and hold these stocks for either 5,20 , or 250 trading days. We examined returns assuming that the purchase was made at close on the announcement day and also assuming that the purchase was made at close on the day after the announcement day.

- Strategy 3. Using publicly available information, compute the logit model's $p$-values for each NYSE/Amex/OTC-listed company. Buy each company with a $p$-value of greater than 0.5 and hold the stock until either the $e x$ dividend date or until a recomputation of the $p$-value based on publicly available information results in a $p$-value of less than 0.5 .

Performance of Strategy 1: Purchase of All Non-Dividend-Paying Stocks. The simplest portfolio based on dividend information to consider using is a portfolio of the stocks of companies that have never paid a dividend. Beginning with data from 1972, we constructed an equal-weighted portfolio of all stocks in the combined 1994 CRSP NYSE/Amex/OTC stock files that had never paid a dividend and that had been trading for at least 500 days. The study required an initial 500-day dividend-free trading period for two reasons. First, the requirement allowed for time after the initial listing to determine that the company was actually a non-dividend-paying stock. Second, the requirement was expected to reduce any confounding effects that might arise from the companies' status as newly listed.

The portfolio was rebalanced daily, and stocks were held either until they were delisted and removed from the data set or until 250 days after the date of the initial dividend announcement. Thus, this portfolio contained some stocks that eventually declared initial dividends and some stocks that never paid a dividend. In total, during the 22-year study period of 1972 through 1993, 7,191 stocks entered the portfolio. Of these, 1,441 declared an initial dividend before the end of 1993 and 3,429 were removed from the CRSP files because of 
mergers, liquidations, or exchange delistings. The rest of the firms continued to be non-dividend-paying companies through 1993.

We calculated excess (abnormal) returns for this portfolio by first estimating the market model coefficients from the ordinary least squares regression:

$$
R_{P, t}=\alpha_{P}+\beta_{P} R_{M, t}+\epsilon_{P, t}
$$

where $R_{P, t}$ is the portfolio return on Date $t$ and $R_{M, t}$ is the CRSP combined NYSE/Amex/OTC equal-weighted return with dividends. Because the portfolio changed composition on a daily basis, the estimates of $\alpha$ and $\beta$ changed over time. To accommodate this potential nonstationarity, the portfolio $\alpha$ and $\beta$ coefficients were estimated every 10 days using the previous 250 days of return data.

We then calculated portfolio excess returns for each day as

$$
X R_{P, t}=R_{P, t}+\hat{\alpha}_{t}-\hat{\beta}_{t} R_{M, t},
$$

where $\hat{\alpha}_{t}$ and $\hat{\beta}_{t}$ are the estimated parameters that apply to Day $t$.

We then aggregated the data for each Year $Y$ :

$$
R_{P, Y}=\prod_{t \in Y}\left(1+R_{P, t}\right)-1
$$

and

$$
X R_{P, Y}=\prod_{t \in Y}\left(1+X R_{P, t}\right)-1,
$$

where the products are taken over the days in the year; therefore, $X R_{P, Y}$ is a compound excess rate of return. The null hypothesis is an equal probability in any year of a positive or negative excess return at the 10 percent level.

Table 14 shows the average number of stocks in the portfolio, the annual portfolio return, the annual portfolio excess return, and the average rolling portfolio betas in each year for the 1972-93 period. For comparison, the table also includes the CRSP equal-weighted return. The average number of stocks in the portfolio ranged from a low of 498 in 1972 to more than 2,400 in 1990 , with a mean of 1,514 stocks. The average portfolio beta was greater than 1.0 in each year, which is consistent with the conventional wisdom that riskier growth companies are less likely to pay dividends than safer, more mature companies. Because daily data were used in estimating $\alpha$ and $\beta$, under the capital asset pricing model (CAPM), the 0.00021 average portfolio alpha should proxy for the daily value of $(1-\beta) \times$ (Average risk-free rate). Thus, $\alpha$ should be negative if $\beta$ is greater than 
Table 14. Returns and Descriptive Statistics for Strategy 1: Portfolio of All Non-Dividend-Paying Stocks on the NYSE/Amex/OTC

\begin{tabular}{lcccccc}
\hline $\begin{array}{l}\text { Year or } \\
\text { Statistic }\end{array}$ & $\begin{array}{c}\text { Number of } \\
\text { Companies }\end{array}$ & $\begin{array}{c}\text { Portfolio } \\
\text { Return }\end{array}$ & $\begin{array}{c}\text { Excess } \\
\text { Return }\end{array}$ & $\begin{array}{c}\text { CRSP Equal- } \\
\text { Weighted Index }\end{array}$ & Alpha & Beta \\
\hline 1972 & 498 & $5.37 \%$ & $-2.30 \%$ & $8.85 \%$ & -0.00032 & 1.38 \\
1973 & 534 & -34.48 & 18.12 & -33.92 & 0.00013 & 1.46 \\
1974 & 593 & -14.48 & -0.48 & -21.37 & 0.00172 & 1.53 \\
1975 & 1,446 & 97.86 & -13.10 & 71.55 & 0.00073 & 1.26 \\
1976 & 1,367 & 70.06 & -0.66 & 54.03 & 0.00029 & 1.16 \\
1977 & 1,198 & 42.70 & 4.30 & 26.46 & 0.00031 & 1.17 \\
1978 & 1,031 & 48.60 & 0.55 & 28.29 & 0.00088 & 1.17 \\
1979 & 958 & 63.41 & 0.13 & 44.01 & 0.00022 & 1.28 \\
1980 & 934 & 65.85 & -1.57 & 44.84 & 0.00047 & 1.24 \\
1981 & 974 & -8.96 & -8.35 & 0.75 & -0.00014 & 1.23 \\
1982 & 1,090 & 21.50 & -1.49 & 26.76 & -0.00058 & 1.23 \\
1983 & 1,413 & 41.34 & 1.15 & 38.76 & -0.00039 & 1.19 \\
1984 & 1,561 & -21.55 & -3.13 & -8.70 & -0.00082 & 1.16 \\
1985 & 1,713 & 20.90 & 3.89 & 28.70 & -0.00105 & 1.15 \\
1986 & 2,012 & 8.85 & 1.47 & 12.23 & -0.00051 & 1.07 \\
1987 & 2,047 & 2.82 & 1.85 & -0.30 & 0.00013 & 1.05 \\
1988 & 2,218 & 35.02 & 0.40 & 30.53 & 0.00007 & 1.09 \\
1989 & 2,462 & 24.13 & 0.69 & 20.49 & 0.00006 & 1.10 \\
1990 & 2,436 & -0.27 & 4.16 & -7.27 & 0.00034 & 1.12 \\
1991 & 2,341 & 120.35 & 2.27 & 79.58 & 0.00097 & 1.11 \\
1992 & 2,250 & 110.65 & 7.30 & 61.60 & 0.00091 & 1.17 \\
1993 & 2,236 & 99.38 & -1.76 & 54.98 & 0.00127 & 1.25 \\
Mean & 1,514 & 36.32 & 0.61 & 25.49 & 0.00021 & 1.21 \\
Standard deviation & & 0.0578 & & 0.00069 & \\
$t$-statistic & & & 0.4956 & & 1.45626 & \\
\hline
\end{tabular}

Note: The $t$-statistic is for the test of whether the mean value of the variable is equal to zero.

1.0. In fact, if $\alpha$ is annualized by multiplying by 250 , it is 5.25 percent for this portfolio, which indicates, under the CAPM, that the portfolio performance in the estimation period was in excess of that predicted by only the portfolio's covariance with the market. As we will show, this large alpha tends to make even large returns not significantly different from zero after risk adjustment.

The interesting observation is that the portfolio returns, ranging up to 120 percent in 1991, are very large for most years; only 5 of the 22 years showed negative returns, and of those 5 , the CRSP equal-weighted return was also negative in 4 . The average annual portfolio return during the period was 36.3 percent, compared with an average annual return of 25.5 percent for the CRSP equalweighted index.

Because of the large portfolio beta and alpha, the portfolio's excess returns were much more modest in size than its absolute returns, but they were positive in 13 of the 22 years. The average annual portfolio excess return, however, at 
Table 15. Returns and Descriptive Statistics for Strategy 1: Portfolio of All Non-Dividend-Paying Stocks on the NYSE/Amex Only

\begin{tabular}{|c|c|c|c|c|c|c|}
\hline $\begin{array}{l}\text { Year or } \\
\text { Statistic }\end{array}$ & $\begin{array}{l}\text { Number of } \\
\text { Companies }\end{array}$ & $\begin{array}{l}\text { Portfolio } \\
\text { Return }\end{array}$ & $\begin{array}{l}\text { Excess } \\
\text { Return }\end{array}$ & $\begin{array}{c}\text { CRSP Equal- } \\
\text { Weighted Index }\end{array}$ & Alpha & Beta \\
\hline 1972 & 466 & $6.71 \%$ & $-1.61 \%$ & $8.85 \%$ & -0.00027 & 1.39 \\
\hline 1973 & 502 & -34.25 & 18.06 & -33.92 & 0.00021 & 1.48 \\
\hline 1974 & 513 & -12.64 & 1.32 & -21.37 & 0.00176 & 1.53 \\
\hline 1975 & 668 & 115.79 & -13.05 & 71.55 & 0.00102 & 1.45 \\
\hline 1976 & 610 & 85.70 & -1.05 & 54.03 & -0.00013 & 1.52 \\
\hline 1977 & 515 & 43.16 & 2.67 & 26.46 & -0.00024 & 1.55 \\
\hline 1978 & 414 & 52.54 & 3.26 & 28.29 & 0.00018 & 1.55 \\
\hline 1979 & 357 & 72.93 & -0.73 & 44.01 & -0.00021 & 1.63 \\
\hline 1980 & 323 & 80.17 & -0.71 & 44.84 & 0.00038 & 1.49 \\
\hline 1981 & 308 & 0.87 & -0.52 & 0.75 & 0.00004 & 1.50 \\
\hline 1982 & 305 & 33.94 & -7.00 & 26.76 & 0.00012 & 1.51 \\
\hline 1983 & 353 & 50.58 & 4.61 & 38.76 & -0.00094 & 1.49 \\
\hline 1984 & 375 & -14.29 & -2.86 & -8.70 & 0.00006 & 1.45 \\
\hline 1985 & 393 & 38.24 & 3.29 & 28.70 & -0.00059 & 1.44 \\
\hline 1986 & 435 & 20.44 & 1.64 & 12.23 & -0.00001 & 1.44 \\
\hline 1987 & 447 & 4.11 & 3.37 & -0.30 & 0.00024 & 1.37 \\
\hline 1988 & 476 & 36.64 & -7.24 & 30.53 & 0.00003 & 1.43 \\
\hline 1989 & 546 & 33.24 & 2.56 & 20.49 & 0.00013 & 1.35 \\
\hline 1990 & 552 & -4.55 & 2.24 & -7.27 & 0.00033 & 1.42 \\
\hline 1991 & 531 & 137.91 & -4.68 & 79.58 & 0.00063 & 1.43 \\
\hline 1992 & 512 & 71.58 & -9.93 & 61.60 & -0.00012 & 1.38 \\
\hline 1993 & 517 & 48.88 & -0.26 & 54.98 & -0.00132 & 1.30 \\
\hline \multicolumn{2}{|c|}{$\begin{array}{l}\text { Mean } 460 \\
\text { Standard deviation } \\
t \text {-statistic }\end{array}$} & 39.44 & $\begin{array}{r}-0.30 \\
0.0620 \\
-0.2274\end{array}$ & 25.49 & $\begin{array}{l}0.00006 \\
0.00062 \\
0.44729\end{array}$ & 1.46 \\
\hline
\end{tabular}

Note: The $t$-statistic is for the test of whether the mean value of the variable is equal to zero.

only 0.6 percent a year, is not significantly different from zero.

Table 15 shows the Strategy 1 portfolio results when we restricted stocks to those last traded on the NYSE or Amex. The mean number of stocks in the portfolio drops to 460 , with a mean annual return of 39 percent. The mean portfolio beta is larger than for the portfolio including OTC stocks, and the mean excess return is negative, although not significantly so.

The results for the portfolio of OTC-only stocks are shown in Table 16 . The mean return is 33.25 percent, but the mean beta, at 1.07 , is substantially lower for these stocks than for the NYSE/Amex portfolio of stocks (1.46). The mean excess return is positive but not significantly so. The excess returns were positive in 15 of the 22 years, a significantly greater percentage than would be 
Table 16. Returns and Descriptive Statistics for Strategy 1: Portfolio of All Non-Dividend-Paying Stocks on the OTC Only

\begin{tabular}{|c|c|c|c|c|c|c|}
\hline $\begin{array}{l}\text { Year or } \\
\text { Statistic }\end{array}$ & $\begin{array}{l}\text { Number of } \\
\text { Companies }\end{array}$ & $\begin{array}{l}\text { Portfolio } \\
\text { Return }\end{array}$ & $\begin{array}{l}\text { Excess } \\
\text { Return }\end{array}$ & $\begin{array}{c}\text { CRSP Equal- } \\
\text { Weighted Index }\end{array}$ & Alpha & Beta \\
\hline 1972 & 32 & $-13.55 \%$ & $-12.94 \%$ & $8.85 \%$ & -0.00105 & 1.31 \\
\hline 1973 & 32 & -38.98 & 17.47 & -33.92 & -0.00112 & 1.25 \\
\hline 1974 & 79 & -17.90 & 1.62 & -21.37 & 0.00122 & 1.50 \\
\hline 1975 & 779 & 82.80 & -5.86 & 71.55 & 0.00041 & 1.00 \\
\hline 1976 & 757 & 58.19 & 0.01 & 54.03 & 0.00065 & 0.87 \\
\hline 1977 & 684 & 42.31 & 5.63 & 26.46 & 0.00074 & 0.87 \\
\hline 1978 & 617 & 45.57 & -1.19 & 28.29 & 0.00137 & 0.91 \\
\hline 1979 & 601 & 57.76 & 0.80 & 44.01 & 0.00049 & 1.06 \\
\hline 1980 & 611 & 58.62 & -1.89 & 44.84 & 0.00052 & 1.11 \\
\hline 1981 & 666 & -13.23 & -11.73 & 0.75 & -0.00022 & 1.09 \\
\hline 1982 & 785 & 17.14 & 1.32 & 26.76 & -0.00088 & 1.11 \\
\hline 1983 & 1,060 & 38.40 & 0.32 & 38.76 & -0.00019 & 1.08 \\
\hline 1984 & 1,186 & -23.75 & -3.23 & -8.70 & -0.00110 & 1.06 \\
\hline 1985 & 1,321 & 16.23 & 4.32 & 28.70 & -0.00120 & 1.06 \\
\hline 1986 & 1,577 & 5.80 & 1.51 & 12.23 & -0.00065 & 0.97 \\
\hline 1987 & 1,600 & 2.27 & 1.35 & -0.30 & 0.00010 & 0.96 \\
\hline 1988 & 1,742 & 34.53 & 2.59 & 30.53 & 0.00008 & 0.99 \\
\hline 1989 & 1,917 & 21.61 & 0.09 & 20.49 & 0.00004 & 1.03 \\
\hline 1990 & 1,883 & 0.95 & 4.69 & -7.27 & 0.00034 & 1.03 \\
\hline 1991 & 1,810 & 115.37 & 4.39 & 79.58 & 0.00107 & 1.01 \\
\hline 1992 & 1,738 & 123.73 & 12.93 & 61.60 & 0.00121 & 1.11 \\
\hline 1993 & 1,719 & 117.63 & -2.18 & 54.98 & 0.00205 & 1.24 \\
\hline \multicolumn{2}{|c|}{$\begin{array}{l}\text { Standard deviation } \\
t \text {-statistic }\end{array}$} & 33.25 & $\begin{array}{l}0.91 \\
0.0662 \\
0.6444\end{array}$ & 25.49 & $\begin{array}{l}0.00018 \\
0.00091 \\
0.90454\end{array}$ & 1.07 \\
\hline
\end{tabular}

Note: The $t$-statistic is for the test of whether the mean value of the variable is equal to zero.

expected under the null hypothesis.

These results indicate that a strategy of investing in non-dividend-paying stocks in hopes of capturing and realizing the excess returns from those that do eventually initiate dividends does not earn significant excess risk-adjusted returns. The excess returns to the portfolio of non-dividend-paying OTC companies are more likely to be positive than negative but are still not statistically significantly positive.

Performance of Strategy 2: Postannouncement Purchase of Dividend-Initiating Companies. In this section, we examine the performance of a portfolio consisting of companies that recently announced an initial 
dividend. Rather than constructing a portfolio in event time, as in earlier sections, this portfolio is constructed in calendar time. This approach allows tracking the actual performance over time of an investment strategy of purchasing all stocks as soon as they announce a dividend initiation. The sample of dividend-initiating companies is the same as in the previous sections, so we were able to form portfolios for the years 1972 through 1989.

The results from the previous sections suggest that the vast majority of the excess returns accruing to dividend-initiating stocks occur in the first five days after the announcement (with somewhat smaller excess returns accruing during the following year). The downside to holding stocks for only five days is that no investment would exist for many days and for those days with investment, few stocks would be held-typically, only one stock would be held at any time. The result is a severely undiversified portfolio. Additionally, the frequent trading might result in large commission fees relative to the holding-period return.

A way to mitigate the diversification and holding-period problems is to hold the stocks for longer than five days. Therefore, we examined three portfolios with different holding periods: 5 days, 20 days, and 250 days. We also considered two levels of round-trip commission fees-no commission and a 1 percent commission. For simplicity, we took the entire round-trip commission at the purchase.

As discussed previously, a substantial amount of the five-day abnormal return occurs on the announcement date, which would require that the stock be purchased at the close on the announcement day. Therefore, we examined how a delay in purchasing the stock affects the portfolio returns by forming portfolios using the Day +1 return and portfolios that omitted the Day +1 return.

Each portfolio was constructed by forming, on each day, an equal-weighted portfolio of all stocks that qualified for inclusion. For the five-day holding period, this approach usually meant investing all of the current capital in the dividendinitiating stock, holding the stock for five trading days, and liquidating the position. The remaining capital was then invested in the next dividend-initiating stock when it made its announcement. For the five-day holding period, if another stock announced a dividend initiation before the five days were up, we reallocated the total capital equally between the first stock and the new entry. For longer holding periods, we rebalanced the portfolio on a daily basis so that an equal amount of money was invested in each stock that qualified for inclusion on that day.

We used a market model adjustment for each stock to calculate excess returns. We excluded the 10-day window before the announcement from the estimation period in order to limit exposure of the returns to information leaks prior to the announcement. Therefore, alpha and beta parameters were estimat- 
ed relative to the CRSP NYSE/Amex/OTC equal-weighted index for Days -260 to -10 , with Day 0 the announcement date. We then calculated excess returns as

$$
X R_{i, t}=R_{i, t}-\hat{\alpha}_{i}-\hat{\beta}_{i} R_{M, t} .
$$

The portfolio excess return was defined as the equal-weighted excess return of all stocks in the portfolio on each day. We used the method of estimating market model parameters and calculating excess returns on individual stocks in the portfolio rather than on the portfolio as a whole because the portfolio composition changed so dramatically over time that its market model parameters were highly nonstationary.

The daily portfolio returns and excess returns were then compounded for each year. The average number of stocks in the portfolio and the return to the equal-weighted index were also calculated for each year.

NYSE/Amex stocks. Table 17 shows the returns to a portfolio of dividendinitiating NYSE/Amex stocks under the assumptions of no commission and realization of the Day +1 return. The entries in the columns for $N 5, N 20$, and $N 250$ show the average portfolio size and vary according to the number of companies declaring initial dividends in each year. ${ }^{6}$ Relatively more companies declared initial dividends during the middle 1970s, and relatively fewer companies did so during the middle 1980 s, leading to relatively large portfolios with 250-day holding periods from 1972 through 1978 and relatively small portfolios from 1984 through 1989.

The average returns to the 5-day, 20-day, and 250-day portfolios are, respectively, approximately 45.3 percent, 27.9 percent, and 30.9 percent. When adjusted for risk, the resulting excess returns are 28.1 percent, 0.1 percent, and -6.3 percent. Consistent with the event study results, the portfolio with 5-day holding periods has outstanding returns, ranging up to almost 200 percent in 1976. The excess return to the 5 -day portfolio is significant at the 5 percent level. The excess returns to the 20-day and 250-day portfolios are not significantly different from zero.

The frequency of trading for these portfolios naturally leads to the question of whether trading costs would absorb the excess returns earned. Table 18 shows the returns and excess returns to the portfolios when a moderate 1 percent round-trip transaction cost is imposed on the initial trade. The mean return to the 5 -day portiolio is reduced from 45.3 percent to approximately 21.4

\footnotetext{
${ }^{6}$ An average size of 0.2 , for example, means that the portfolio had positive investment, on average, one out of five days. An average size of zero appears in 1989 when the last dividend initiation in the sample occurred in 1988.
} 


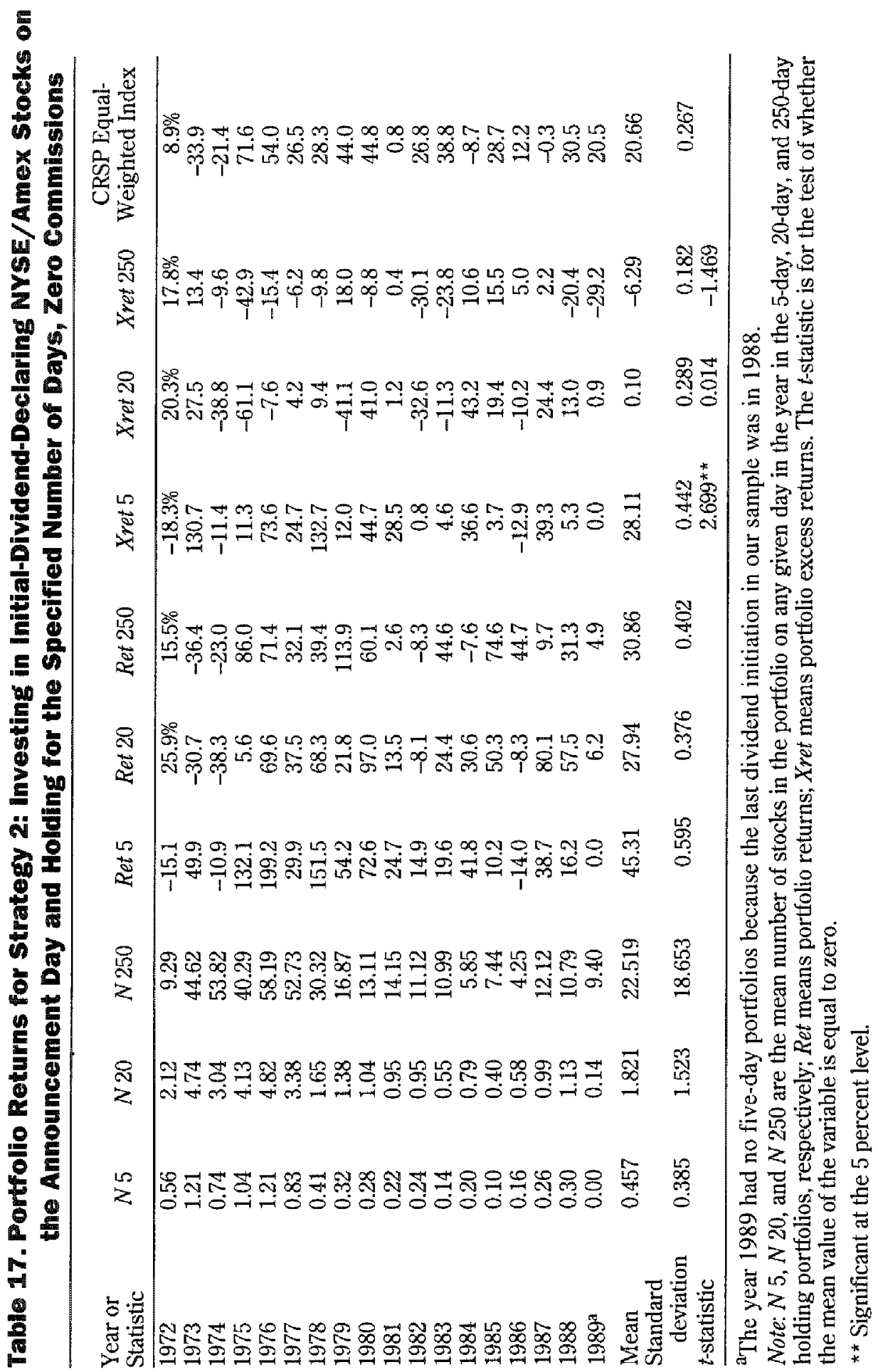




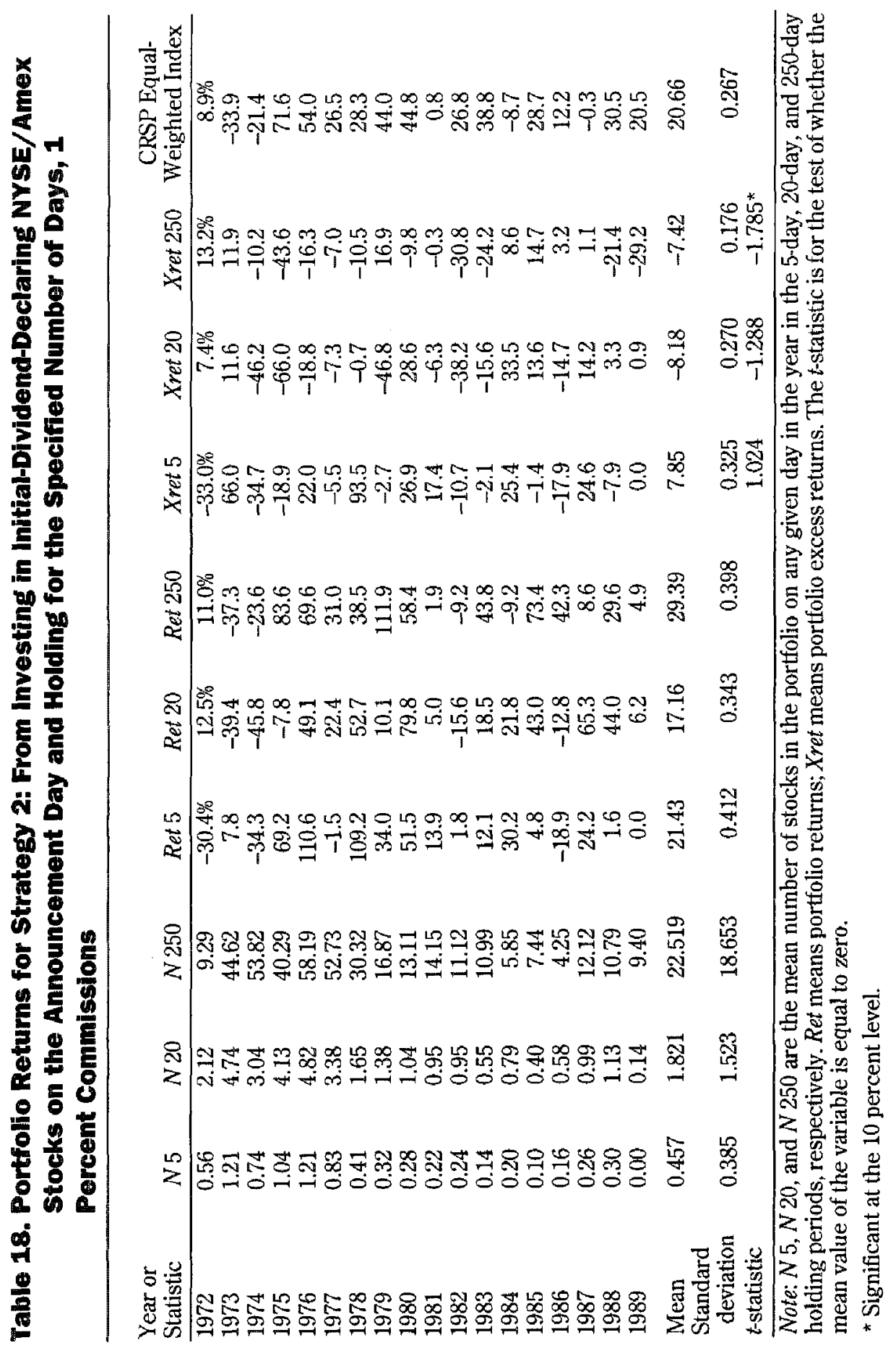

(C)The Research Foundation of the ICFA 
percent; the longer-holding-period portfolios have smaller reductions in returns.

The mean excess return to the 5-day portfolio remains positive after deducting transaction costs, but the value is not significantly different from zero. Thus, even though the portfolio constructed by purchasing NYSE/Amex stocks at the close on the announcement day and holding them for 5,20 , or 250 days does earn high rates of return, the inclusion of a minimal transaction cost and risk adjustment makes these returns insignificantly different from zero.

The ability to realize the Day +1 return hinges on learning of the dividendannouncement before the close of the market and being able to enter into a trade at close on the announcement day. A less stringent requirement would be to purchase at the close on the day after the announcement (Day +1 ), thus realizing the Day +2 return but not the Day +1 return. This requirement is perhaps too lax, in that an observant trader would learn about many dividend-initiation announcements before close and act on them that day. Also, other dividendinitiation announcements might occur after the close of the market on the announcement day but the trader would be able to purchase them well before the close on Day +1 .

The event study results showed, on average, a positive return on both Day +1 and Day +2 , which suggests that an observant trader could achieve results somewhere between those obtained assuming the Day +1 return is realized and those obtained assuming the Day +2 day return is realized. Table 19 shows the results for our portfolios under the assumptions that the Day +2 but not the Day +1 return is realized and no commission is paid. Only the excess return to the 5-day holding period portfolio is positive, and this return is not significantly different from zero. The excess return to the 20 -day portfolio is -9.9 percent, which is negative at the 10 percent level of significance. The total return to the 250-day portfolio, at 28.8 percent, is larger than the others, but after risk adjustment, the average excess return is -8.05 percent, which is also negative at the 10 percent level of significance.

15 OTC stocks. The performance of a portfolio of dividend-initiating OTC stocks is somewhat different from that of a portfolio of NYSE and Amex stocks. In general, the levels of excess return for the OTC stocks are higher, as is the significance level. Table 20 shows the returns to a portfolio of dividend-initiating OTC companies when the portfolio is formed on Day +1 and zero commission costs are assumed. The average portfolio sizes are comparable to those formed from the NYSE/Amex sample. The five-day portfolios have an average size ranging from below 0.2 in the early 1980 s to 1.74 in the late $1980 \mathrm{~s}$. The 20-day portfolios are invested in an average of 3 stocks and the 250-day portfolios in an average of 38 stocks at any given time. As with the NYSE/Amex sample, the 5day and the 20-day portfolios are poorly diversified. 


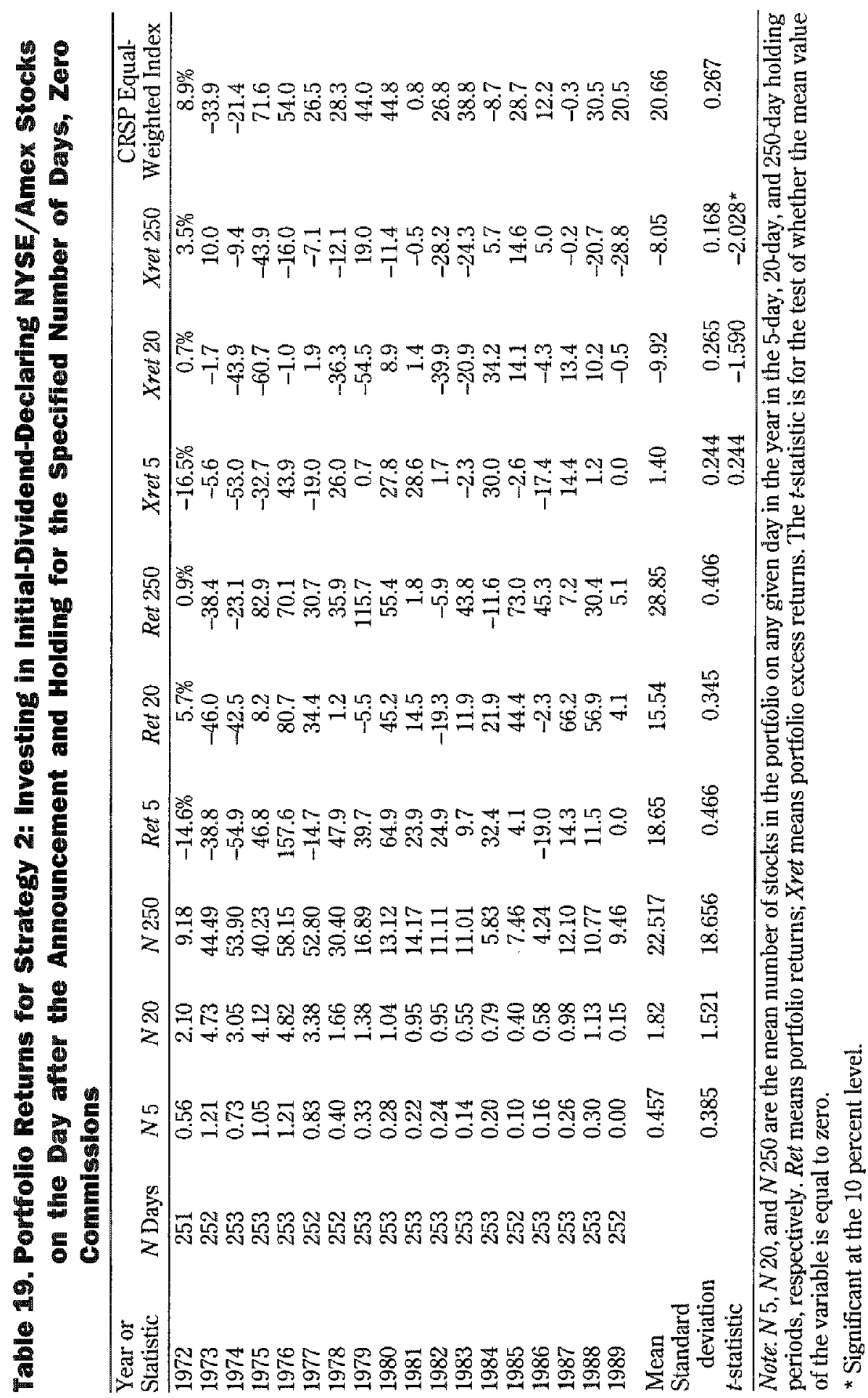

(CThe Research Foundation of the ICFA 


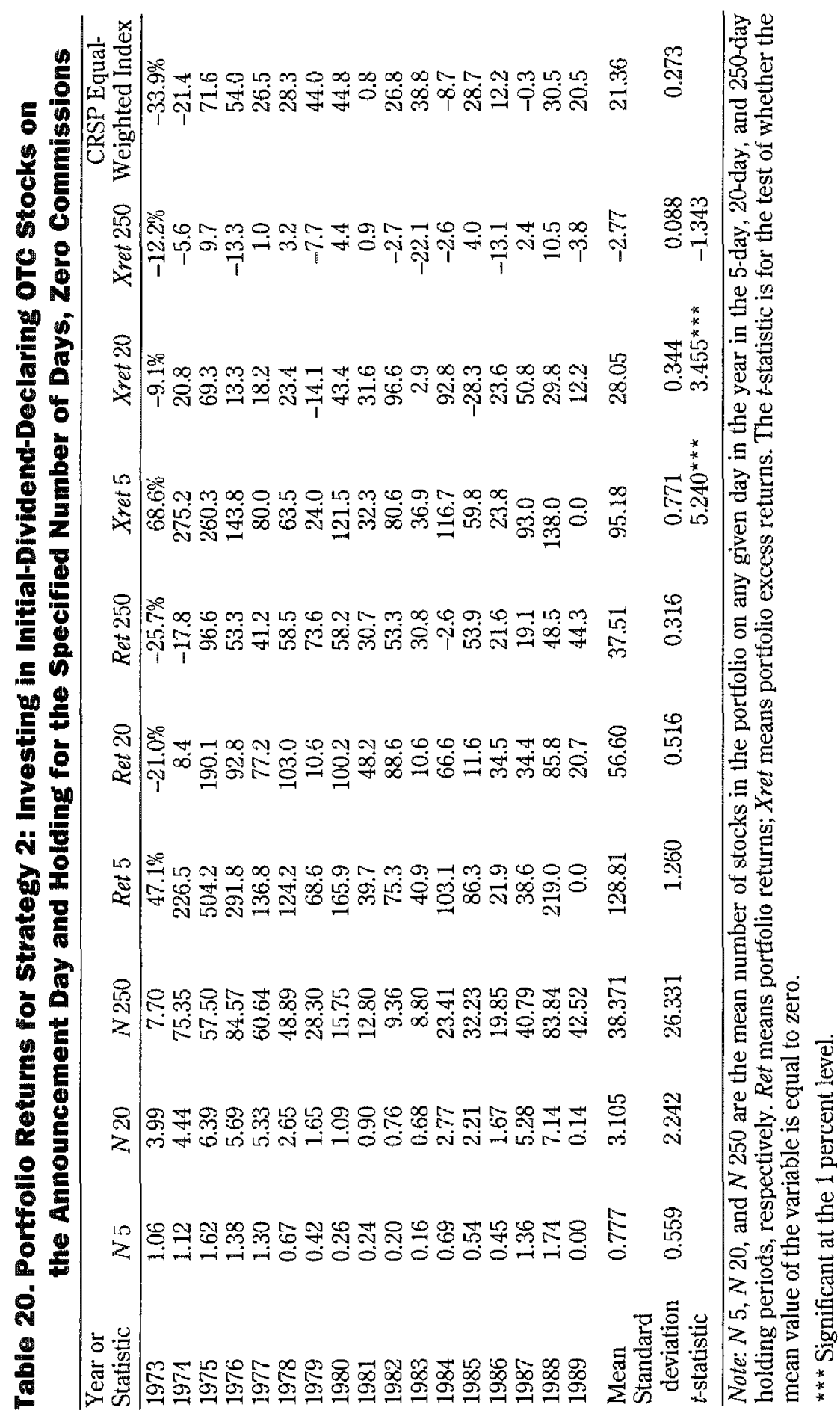


Table 20 also shows that the returns to the five-day portfolio range from a low of 21 percent in 1986 to a remarkable high of 504 percent in 1975. In no year was the annual return negative, and the average annual return was 128 percent. The longer-holding-period portfolios also performed well. The 20-day portfolio averaged 56 percent, with only one negative-return year, and the 250-day portfolio averaged 37 percent, with only three negative-return years.

The excess returns to the 5- and 20-day portfolios are also large and significant. The average excess return to the 5-day portfolio is 95.2 percent, which is significant with a $t$ of 5.2 , and the average excess return to the 20-day portfolio is 28 percent, significant with a $t$ of 3.45 . The excess return to the 250day portfolio is a negative figure but not significantly so.?

Given the large magnitude of these excess returns (the five-day portfolio produced no negative returns or negative excess returns during the 17-year period), the potential effect of delaying investment and incurring transaction costs is not entirely academic. Table 21 reports the returns and excess returns to the portfolio formed on Day +1 under the assumption of 1 percent commission costs. The returns are still large, and the excess returns to the 5- and 20day portfolios are still significantly positive. The 5-day portfolio's average excess return is 51.4 percent, with a $t$ of 4.7 , and the 20 -day portfolio's average excess return is 16 percent, with a $t$ of 2.21 . The 250-day portfolio would have earned a -3.7 percent excess return, which is significantly negative at the 10 percent level. (Although not reported in Table 21, the imposition of a commission cost of 2 percent left the 5-day portfolio with an average annual return of 36 percent and an average annual excess return of 19.1 percent, significant at the 1 percent level.) In summary, a portfolio constructed by purchasing dividend-initiating OTC stocks by the close on the announcement date and holding the stocks for 5 days appears to yield significantly positive excess returns even after accounting for reasonable transaction costs.

Table 22 shows the effect of delaying the investment to Day +2 with no commission costs. Although not as large as when the Day +1 return was captured, the excess returns to the 5 -day and 20 -day portfolios, at 37.3 percent and 15.5 percent, respectively, are significantly positive. The excess return to the 250-day portfolio is negative and significant.

\footnotetext{
${ }^{7}$ The five-day returns and excess returns for 1974 and 1975 are very large, which leads to the question of whether the significance of the mean excess return is driven by these two years. When 1974 and 1975 are omitted, the mean excess return for 1973 through 1989 drops from 95.18 percent to 72.17 percent but the $t$-statistic for the test of equality to zero is 6.53 , which is significant at the 1 percent level. The excess 20-day return also declines if 1974 and 1975 are omitted, but the average excess return is still positive and is significantly different from zero at the 1 percent level.
} 


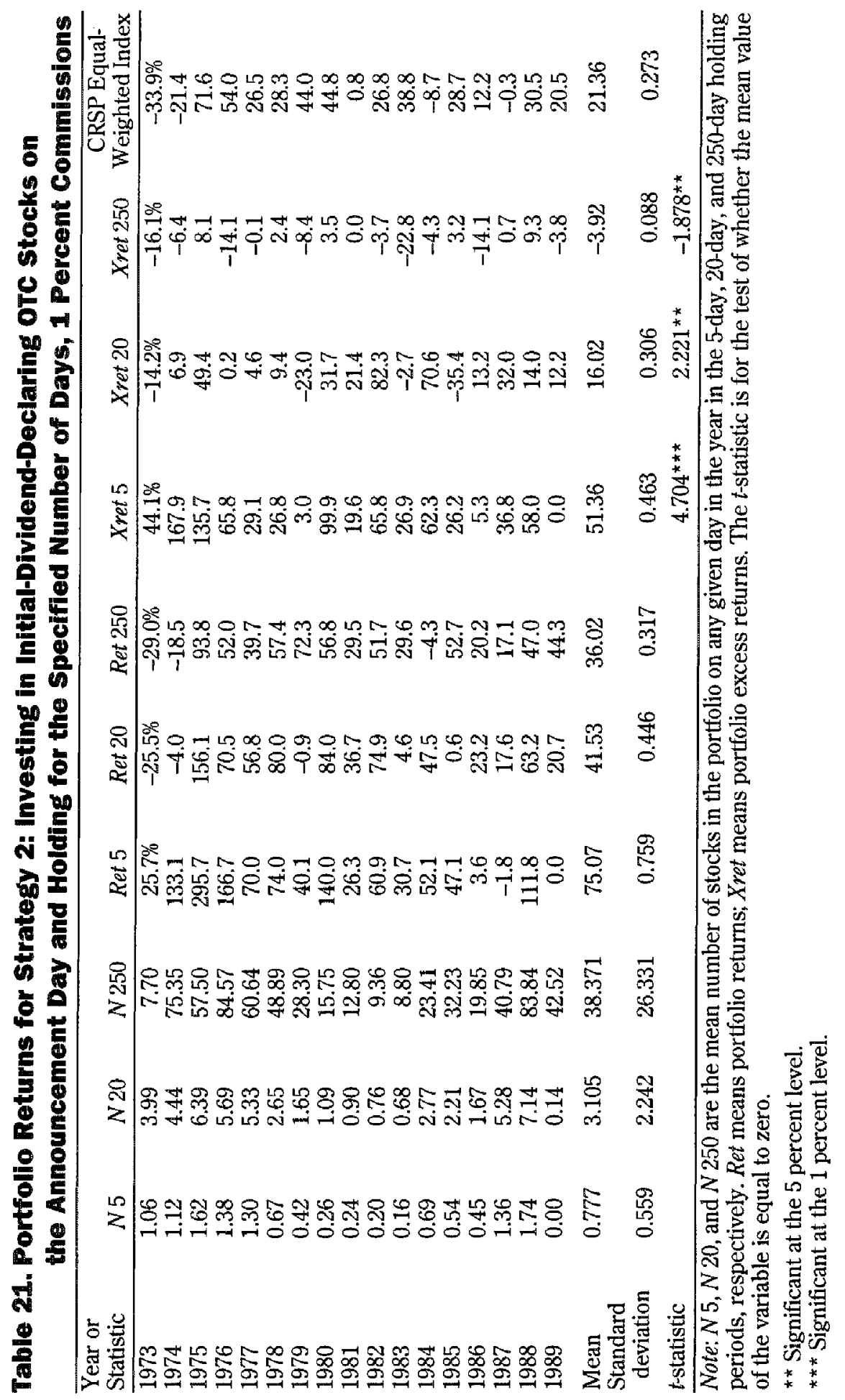




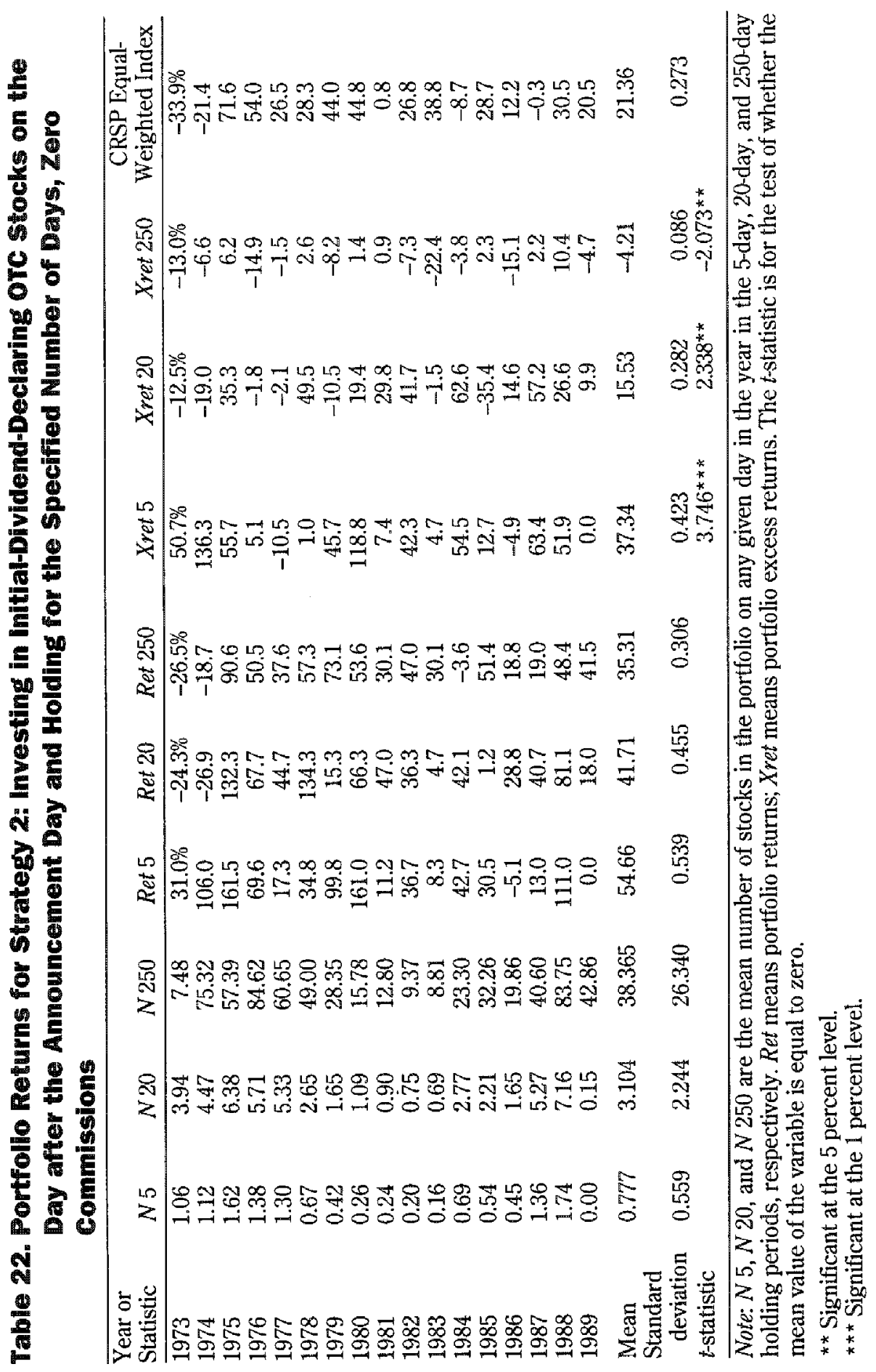


Table 23 shows the effect of imposing a 1 percent commission fee on the portfolio returns in Table 22 . The mean excess returns to the 5-day and 20-day portfolios, at 9.3 percent and 4.7 percent, respectively, are still positive, but they are no longer significant at conventional levels. In fact, the excess return to the 5 -day portfolio is negative in 7 of the 17 years, and a binomial test cannot reject the hypothesis that negative and positive excess returns are equally likely.

In summary, some evidence supports the hypothesis that excess returns can be earned by investing promptly in dividend-initiating companies. In particular, if a trader restricts purchases to OTC stocks, can consistently make a purchase some time before the market close on the day after the initiation announcement, faces round-trip transaction costs on the order of 1 percent, and holds the stocks for five days, the evidence from the 1973-89 data suggests that the trader can earn an average annual excess return of at least 9.3 percent. A trader who holds the stocks for 20 days can earn an average annual excess return of 4.5 percent.

Of course, these portfolios are not by any means well diversified. For the 1973-89 period, the 5-day OTC portfolio averaged an investment in only 0.79 stocks at any time. Expanding the holding period to 20 days to increase the number of stocks held at any time reduced the average return and excess return, and expanding the holding period to a full 250 days reduced the average excess return to less than zero.

The number of stocks at any time depends on the frequency of dividend initiations in the economy. If quite a few dividend initiations were to occur in some time period, then the portfolio for that period would be relatively more diversified. Past data suggest, however, that a five-day holding period will never result in more than two or three stocks held at any given time.

Performance of Strategy 3: Portfolios Formed on the Basis of Predicted Dividend Initiation. The results of the preceding portfolio simulations show that a strategy of investing in all non-dividend-paying companies is not specific enough to realize the excess returns associated with dividend initiation and that, although the strategy of investing in dividend-initiating companies just after the initiation announcement can yield significantly positive excess returns, the portfolio sizes are rather small, resulting in an investment that has a great deal of unsystematic risk. A compromise between the large portfolio size obtained when selecting all non-dividend-paying companies and the large excess returns but small portfolio size when only stocks that have just recently initiated dividend payments are selected is to select only those stocks that are expected to initiate dividend payments.

The results of the logit model estimation showed that significant changes occur in the accounting-based measures for dividend-initiating companies in the 


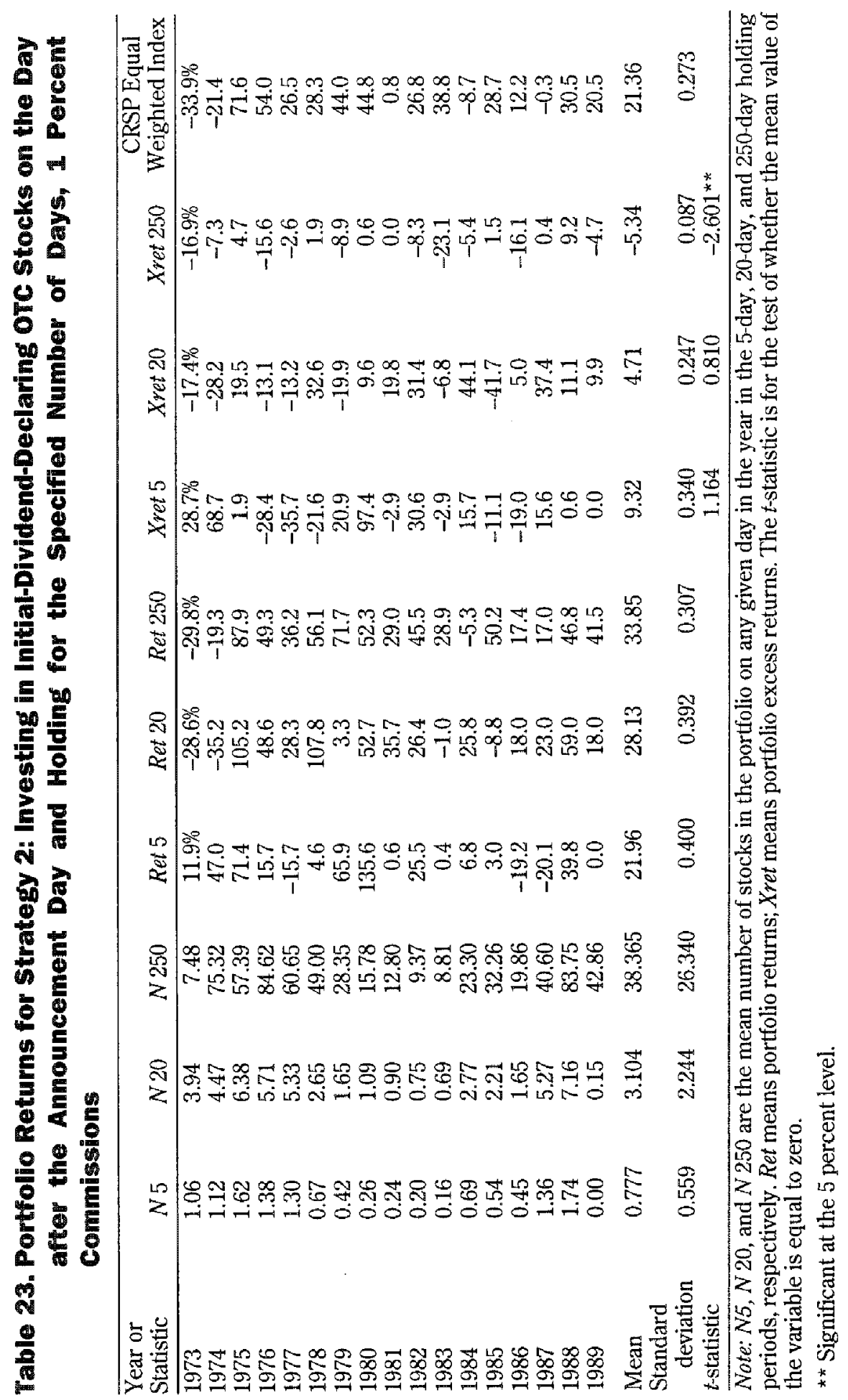


years immediately prior to dividend initiation. Therefore, our study now turns to whether these results may be useful in capturing the returns theoretically associated with dividend initiation. The dividend-initiation model developed previously examined changes in accounting measures between Year $t-1$ and Year $t-2$ and between Year $t-1$ and Year $t-3$ for the entire sample of dividendinitiating companies. We also examined the subsample of companies with a positive three-day cumulative excess return around the announcement and the subsample of companies with a negative three-day cumulative excess return around the announcement. The result was a total of six sets of logit regressions.

For the current portion of the study, we used the coefficients from these logit regressions in portfolio construction to predict, for a sample of nondividend-paying stocks, which stocks would be most likely to initiate dividends. Specifically, we used the parameters estimated from our sample of dividendinitiating companies from 1972 through 1988 on a separate sample of nondividend-paying stocks from 1989 through 1993 to select stocks for the portfolio.

In order to be considered for inclusion in the portfolio, a company had to have valid returns on CRSP and must not have paid a dividend prior to 1989 . This sample was then narrowed to companies for which the required independent variables were available on Compustat. To ensure that the accounting information would actually be available for use in constructing a portfolio, a company whose predicted probability qualified it for inclusion in the portfolio was not added until the beginning of the fourth month after the month of the fiscal year; for example, a company with a fiscal year ending December 31 would not be included in the sample until April 1.

To identify the companies for the portfolios, we defined $\hat{\beta}$ as the set of regression coefficients from the logit regression, $X_{j, t}$ as the set of values of the independent variables for Company $j$ and Year $t$, and $\alpha$ as the estimated intercept for the model. The estimated probability in Year $t$ that Company $j$ will initiate dividend payments was then

$$
p_{j, t}=\frac{1}{1+e^{-\hat{\alpha}-X_{j, t} \hat{\beta}}} .
$$

Companies for which $p_{j, t}$ was greater than 0.5 were included in the portfolio. The result was a portfolio of all companies for which data would have been available and which were predicted to initiate dividends.

Each company in the portfolio was held for one year or until the $e x$-dividend date. If a company did not pay a dividend during the year, its probability was then recalculated based on the new accounting information, and it was included in the portfolio for another year if it again qualified for inclusion. 
For each day from January 1, 1989, through December 31, 1993, we calculated the return and excess return for each stock that qualified for inclusion in the portfolio. Excess returns were calculated as previously described, with the use of a market model regression on Days -1 through -251 relative to the date of inclusion in the portfolio and with the CRSP NYSE/Amex/OTC equalweighted index used as the independent variable. An equal-weighted portfolio was then formed, and we calculated the equal-weighted returns and excess returns. We then, as with the previous portfolios, aggregated these returns and excess returns to form monthly returns and monthly excess returns.

The companies' financial characteristics at Time $t-1$ were compared with their characteristics at either Time $t-2$ or Time $t-3$. We made this comparison for all companies and then separately for companies with positive CARs in the first three days after announcement and for companies with negative CARs in the first three days after announcement. The six models are called $(-1,-2),(-1,-3),(-1,-2)^{+},(-1,-3)^{+},(-1,-2)^{-}$, and $(-1,-3)^{-}$; the superscripts refer to the entire sample (no superscript), the subsample with positive CARs (superscript + ), and the subsample with negative CARs (superscript -).

The portfolios based on the six models' predictions were first formed using all NYSE/Amex companies and then again for all OTC companies. The result was 12 possible portfolios. The logit models $(-1,-2)^{-}$and $(-1,-3)^{-}$did not result in any companies to include in any year, however, so only the eight remaining portfolios are analyzed here.

Table 24 shows the mean monthly portfolio return, number of stocks in the portfolio, and estimated portfolio alpha and beta for each of the eight portfolios. The portfolios formed with NYSE/Amex companies, varying from an average of 44 for the $(-1,-2)^{+}$model to an average of 120 for the $(-1,-3)$ model, have the fewest members. The more populated OTC portfolios varied from 127 for the $(-1,-2)$ portfolio to 266 for the $(-1,-3)$ portfolio. As might be expected from samples of non-dividend-paying stocks, the betas, ranging from 1.14 to 1.49 , are fairly large.

Column 4 of Table 24 shows the mean alphas from the market model regressions on the individual stocks using daily data. Under standard assumptions about the CAPM and a constant risk-free rate, the alpha coefficient should be $r_{f}(1-\beta)$, where $r_{f}$ is the daily risk-free rate for the estimation period. For assets with average betas in excess of 1.0 , the alpha coefficient would be negative. Instead, considering that they are daily alphas, the alphas are again quite large, varying from 0.000211 for the $(-1,-3)$ NYSE/Amex portfolio to 0.001064 for the $(-1,-3)^{+}$OTC portfolio. On an annual basis, the range for alpha is from 5.3 percent to 26.6 percent; the standard CAPM with a constant risk-free 


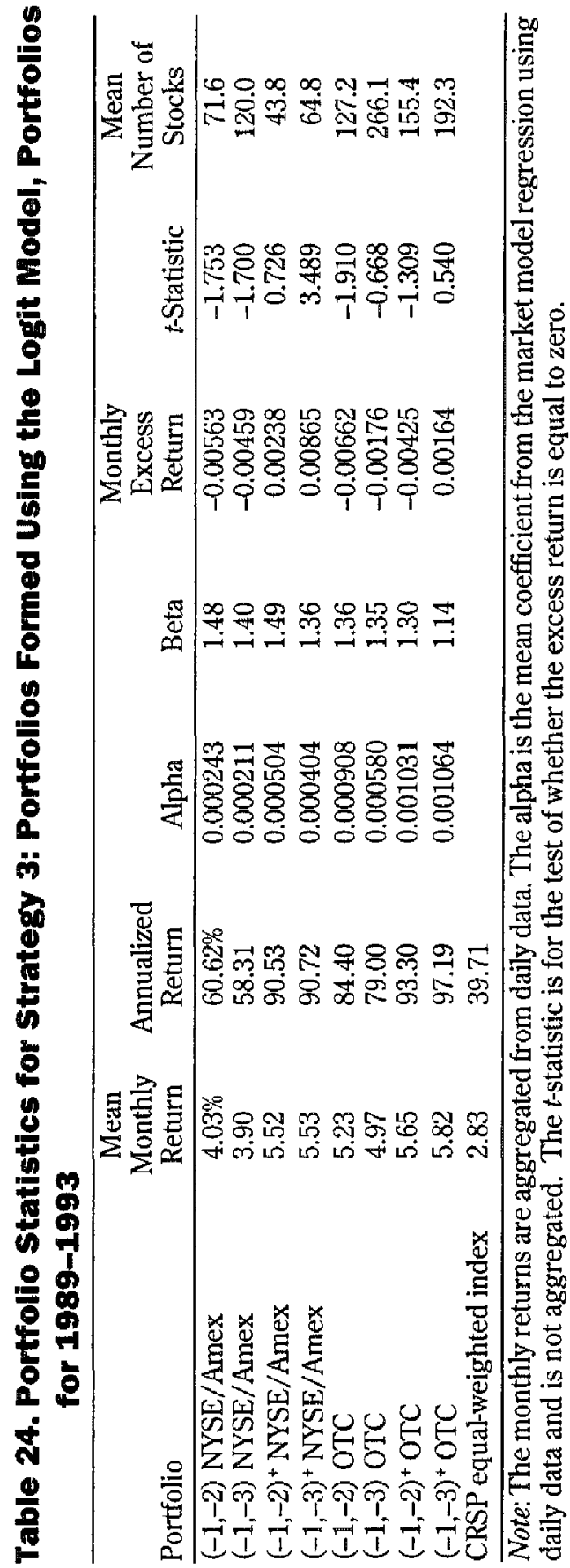


rate of 6 percent and a beta of 1.4 would imply an annual alpha of -0.024 , or -2.4 percent. Therefore, the smallest of our estimated alphas is 7.7 percent larger than the implied alpha, which indicates that the individual stocks in the selected portfolios earned excess returns relative to the market model during the estimation period. As with the portfolio of all non-dividend-paying stocks, however, the large alpha would cause even quite large portfolio returns to be insignificantly different from zero or negative after risk adjustment.

The mean portfolio returns are uniformly greater than the equal-weighted index return and range from 3.9 percent to 5.8 percent a month, with annual values ranging from 58.3 percent to 97.2 percent. After adjusting for market risk, however, the average monthly excess returns range from a low of -0.66 percent for the $(-1,-2)$ OTC portfolio, which is significantly negative, to a high of 0.86 percent for the $(-1,-3)^{+}$NYSE/Amex portfolio, which is significantly positive.

Figure 4 shows the cumulative raw portfolio returns over time for each of the eight portfolios and the CRSP equal-weighted index including dividends (EWRETD); Table 25 shows the cumulative returns as of December 31, 1993. Clearly, the portfolios' cumulative returns are huge relative to the equalweighted index, even if most of the monthly excess returns are not significantly different from zero: $\$ 1.00$ invested in the equal-weighted index at the start of 1989 and held until the end of 1993 would have been worth approximately $\$ 5.03$, a remarkable five-year rate of appreciation and one that was driven primarily by increases in OTC stock prices; $\$ 1.00$ invested in the $(-1,-3)^{+}$ NYSE/Amex portfolio would have grown to $\$ 22.68$, however, and the same $\$ 1.00$ invested in the $(-1,-3)^{+}$OTC portfolio would have grown to $\$ 27.38$.

Figure 5 shows that the cumulative excess returns also contain patterns. The only portfolio with significantly positive excess returns is the $(-1,-3)^{+}$NYSE/ Amex portfolio, and Figure 5 clearly shows how well it performed. The other portfolios have a systematic increase in cumulative excess returns for two years after the logit estimation period, after which their cumulative excess returns start to decline. This pattern suggests that the accuracy of the model begins to decline after two years and that, to obtain better portolio performance, its parameters should be reestimated more frequently than five years, perhaps annually.

In conclusion, certain portfolio strategies based on dividend-initiating stocks can apparently earn significant excess returns. The strategy of buying stocks just after the announcement of a dividend initiation appears to earn excess returns, but realizing those returns requires that the investor be able to identify the stocks within the first day after announcement and face very small transaction costs. The portfolios ultimately formed in such a strategy are severely undiversified, although they performed quite well during the test period. The strategy of identifying candidates for dividend initiation using a logit model pro- 


\section{Figure 4. Cumulative Returns for Logit-Based Portfolios}

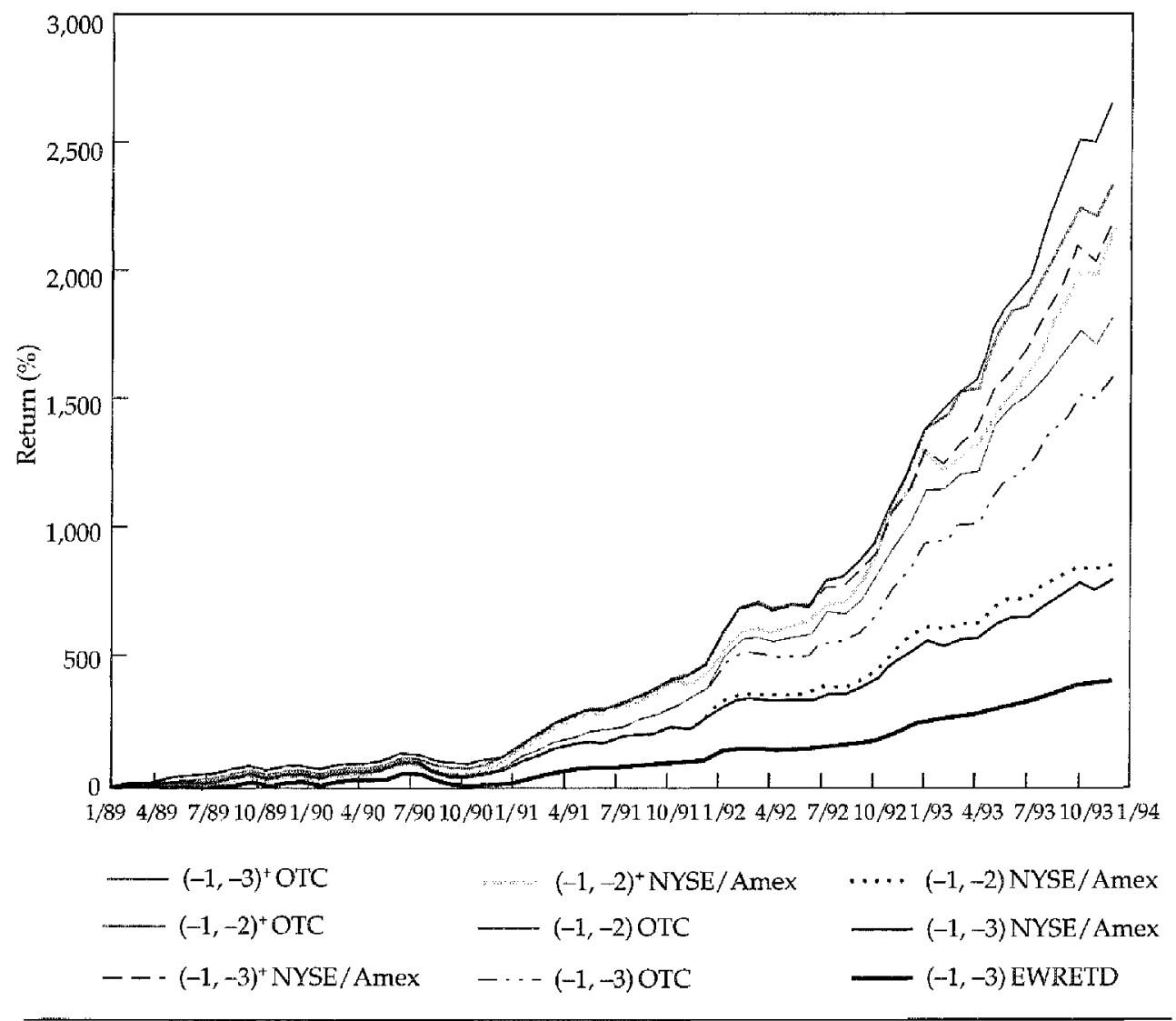

vides positive excess returns and does so with a portfolio containing many stocks. The logit model that compares the companies' financial characteristics three years before initiation with the characteristics in the year before initiation appears to perform the best in identifying superior-performing non-dividendpaying stocks.

\section{Summary}

A company's decision to initiate dividend payments is complicated and means different things in different companies. The motivation for a particular company and the market's response to that particular company appear to be influenced by three factors.

First, some companies that initiate dividends do so only if they anticipate 
Table 25. Ending Portfolio Value after $12 / 31 / 93$ for $\$ 1.00$ Invested, Assuming No Transaction Costs, and All Dividends Reinvested in the Portfolio

\begin{tabular}{lc}
\hline Portfolio & Future Value of $\$ 1,00$ \\
\hline$(-1,-2)$ NYSE/Amex & $\$ 9.59$ \\
$(-1,-3)$ NYSE/Amex & 8.99 \\
$(-1,-2)^{+}$NYSE/Amex & 22.12 \\
$(-1,-3)^{+}$NYSE/Amex & 22.68 \\
$(-1,-2)$ OTC & 19.11 \\
$(-1,-3)$ OTC & 16.75 \\
$(-1,-2)^{+}$OTC & 24.39 \\
$(-1,-3)^{+}$OTC & 27.38 \\
CRSP equal-weighted return & 5.03 \\
\hline
\end{tabular}

being able to continue paying the dividends into the future. In this case, dividend initiation is a signal of continued strong or improving earnings and should be viewed positively by the market.

Second, some companies that initiate dividends appear to do so in response to a decrease in their investment opportunity sets. This observation is consistent with the concept of a hierarchy of capital sources, with internally generated equity at the top; companies with enormous growth opportunities simply cannot afford to pay out dividends. From this perspective, the decision to initiate dividends is a signal that the period of rapid growth has passed and the company is entering a mature phase. This signal is not positive, and the market response to the dividend-initiation information, if the information was unanticipated, may well be negative.

Finally, the decision of a maturing company with excess free cash flow to pay dividends is a signal that the company has decided to return this excess cash flow to its investors rather than waste it. From this perspective, the initiation decision appears to be positive.

We examined the market reaction to dividend initiations, the financial and operational characteristics of companies that chose to initiate dividend payments, and the return characteristics of portfolios based on both dividend initiation and company characteristics. We also segmented our study to consider separately those companies whose dividend initiations elicited positive market responses (positive CARs) and those companies whose initiations received negative market responses (negative CARs). Our findings fit neatly into the three categories. We found that, on average, a positive market response greets companies that initiate dividends but that this response contains substantial cross-sectional variation.

Cluster analysis showed that both the positive- and negative-CAR groups of 
Figure 5. Cumulative Excess Returns for Logit-Based Portfolios

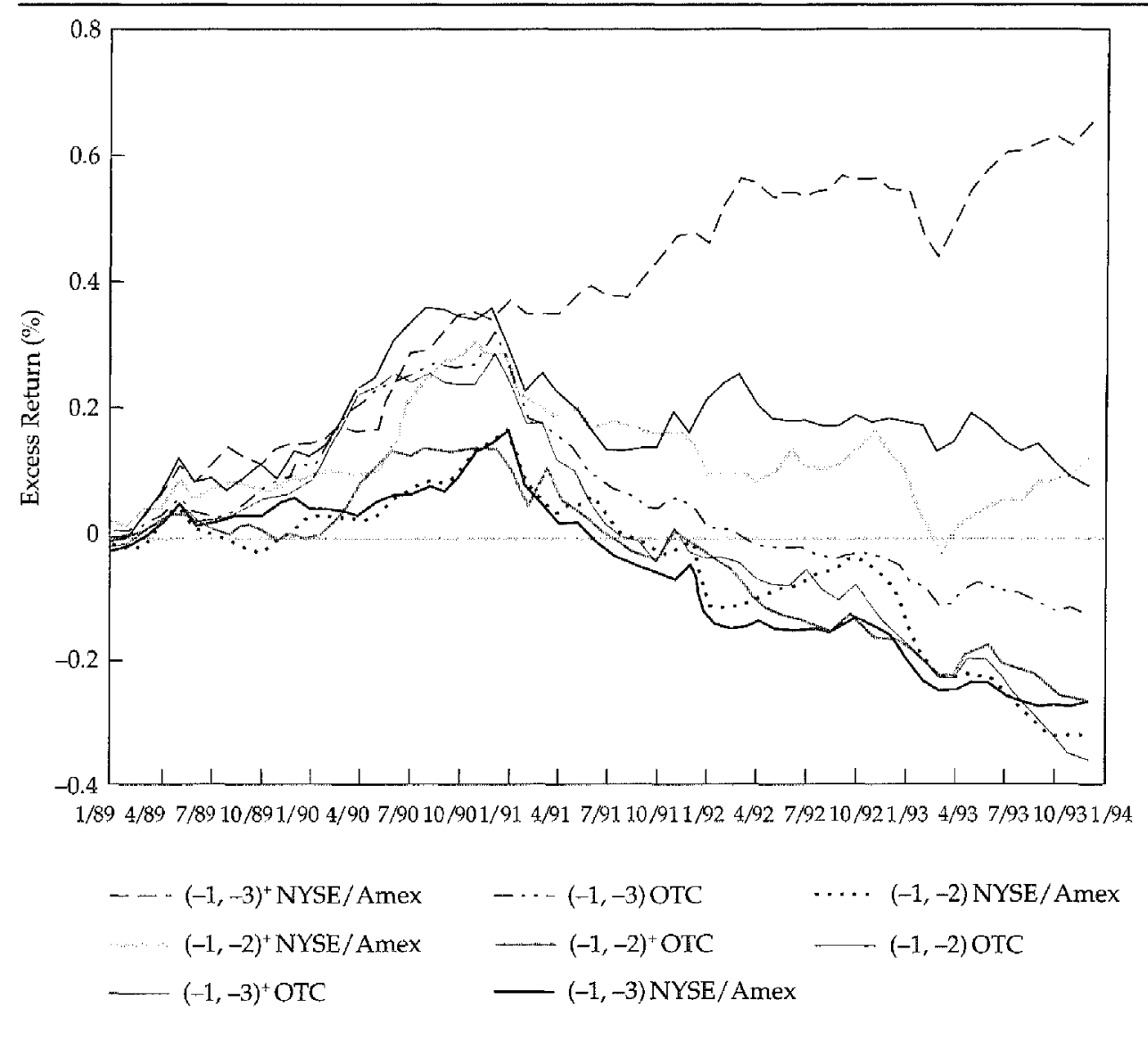

companies exhibited the decreases in investment opportunities and increases in earnings that would accompany movement toward maturation; those companies that had the highest positive market responses, however, were those with the relatively lower $\mathrm{P} / \mathrm{Es}$, cash flows, and profitability and relatively higher leverage. In other words, those companies that already looked like maturing companies, with lower earnings multiples to reflect their status, had the highest positive market response to dividend initiation. For these companies, the dividend initiation did not reveal new information that the investment opportunity set had shrunk; the market already knew that. Instead, the initiation revealed that (1) management would return the unneeded portion of earnings to the investors and (2) the managers believed the company would be able to continue 
paying dividends into the future. For the other companies, the announcement came as an unanticipated and negative signal that the company would not grow in the future as it had in the past.

We also found that significant financial changes occurred in these companies leading up to the dividend initiation that can help investors identify when to expect such an announcement. The univariate tests and the logit estimation procedure showed that the typical dividend-initiating company had recently grown at a decreasing rate, had a declining investment opportunity set, and had a decline in its earnings multiplier. Both the positive-CAR and the negative-CAR groups exhibited these characteristics, although the coefficients from the logit regression were different for the two groups. These results suggest that the logit coefficients can be used in investment strategy to predict when companies might initiate dividends.

Apparently, some profitable investment strategies based on the phenomenon of dividend initiation are possible. A portfolio consisting of all non-dividendpaying stocks does not appear to earn excess returns, but a strategy of identifying and purchasing dividend-initiating OTC stocks on their announcement day and holding the shares 5-20 days appears to earn excess returns, after commissions, of 16-51 percent a year. Portfolios of such stocks are severely undiversified, however; positive investment is often possible in only a single stock and in as few as one day in five. Using the logit model to choose a portfolio of nondividend-paying companies that are likely to declare initial dividends produces more diversified portfolios and, in these tests, produces portfolios with average monthly excess returns ranging from a significant -0.66 percent to a significant 0.86 percent. 



\section{Appendix: Definition of Variables}

The variables are grouped for convenience into the following eight categories, or dimensions. Table A contains a description of the ratios included in each category, a computational definition of each ratio identifying which Compustat data items were used, and the acronym of the variable.

Liquidity. A company must have adequate liquidity, particularly in its cash position, before initiating dividends. Consequently, two estimates of liquidity, CDTCA (measuring the proportion of current assets held as cash) and CURRENT (the traditional current ratio) were included.

Valuation. Valuation ratios are often used in financial analysis when comparing companies. Three measures were used here-one that relates the market value of equity to earnings (PE), one that relates the market value of equity to assets (EV), and one that relates the book value of assets to the market value of equity (CBDMV). These valuation measures overlap those of the next category, the firm's investment opportunity schedule.

Investment opportunities. A company's investment opportunities are not observable outside the company but are considered to be revealed in a variety of measures. For example, the general investment opportunity schedule (IOS) is defined as the book value of assets divided by the market value of equity and is related to future growth opportunities (Chung and Charoenwong 1991); low values denote high expected growth. This measure has also been proposed as a measure of distress, with high values signifying poor prospects (Fama and French 1992).

In addition to IOS, four other ratios are included in this category-RADDS (indicating investment in new or higher-quality products), NPETA (capturing past long-term investment), CEDTA (denoting long-term investment), and NPDD (measuring the average remaining accounting life of the assets).

Size. The size of the firm has been used as a proxy for several concepts. Growth of a company would suggest its ability to realize past investment opportunities. Firm size is also associated with access to debt capital markets, in that large companies are considered to be less risky and have been observed to have more debt financing than small companies. In addition, a common assumption is that less is known about the true condition of small companies than about that of large companies. For these variables, the logarithmic transformation corrects for skewness in the distributions. The size variables are assets (LOGTA), sales (LOGSAL), and market value of equity (LOGMVE). 
Table A. Variable Description and Compustat Definition

\begin{tabular}{|c|c|c|c|c|}
\hline Dimension & Number & $\begin{array}{l}\text { Variable } \\
\text { Description }\end{array}$ & $\begin{array}{l}\text { Compustat } \\
\text { Definition }\end{array}$ & Acronym \\
\hline \multirow[t]{2}{*}{ Liquidity } & 1 & Cash/Total current assets & $1 / 4$ & $\overline{\text { CDTCA }}$ \\
\hline & 2 & Current assets/Current liabilities & $4 / 5$ & CURRENT \\
\hline \multirow[t]{3}{*}{ Valuation } & 3 & $\begin{array}{l}\text { Market value of equity/ (Market } \\
\text { value of equity + Book value of } \\
\text { assets - Book value of equity) }\end{array}$ & $\begin{array}{c}\left(24^{\star 2} 25\right) /\left[\left(\left(24^{*} 25\right)\right.\right. \\
+6-60]\end{array}$ & $\mathrm{EV}$ \\
\hline & 4 & $\begin{array}{l}\text { Price/Fully diluted earnings per } \\
\text { share }\end{array}$ & $24 / 57$ & PE \\
\hline & 5 & $\begin{array}{l}\text { Book value of equity/Market } \\
\text { value of equity }\end{array}$ & $60 /(24 \star 25)$ & CBDMV \\
\hline \multirow[t]{5}{*}{$\begin{array}{l}\text { Investment } \\
\text { opportunity } \\
\text { schedule }\end{array}$} & 6 & $\begin{array}{l}\text { Book value of assets/Market } \\
\text { value of equity }\end{array}$ & $6 /(24 * 25)$ & IOS \\
\hline & 7 & $\begin{array}{l}\text { Net plant and equipment/Total } \\
\text { assets }\end{array}$ & $8 / 6$ & NPETA \\
\hline & 8 & $\begin{array}{l}\text { Research and development } \\
\text { expenses/Sales }\end{array}$ & $46 / 12$ & RADDS \\
\hline & 9 & $\begin{array}{l}\text { Capital expenditures/Total } \\
\text { assets }\end{array}$ & $128 / 6$ & CEDTA \\
\hline & 10 & $\begin{array}{l}\text { Net plant and equipment/ } \\
\text { Depreciation }\end{array}$ & $8 / 14$ & NPDD \\
\hline \multirow[t]{3}{*}{ Firm size } & 11 & Log of total assets & $\log (6)$ & LOGTA \\
\hline & 12 & Log of market value of equity & $\log (24 \star 25)$ & LOGMVE \\
\hline & 13 & Log of sales & $\log (12)$ & LOGSAL \\
\hline Regulation & 14 & Dummy variable & & $\mathrm{REG}$ \\
\hline \multirow[t]{5}{*}{ Profitability } & 15 & Cash flow/Sales & $(18+14+112-116) / 12$ & CFDSA \\
\hline & 16 & Net income/Total assets . . & $172 / 6$ & NIDTA \\
\hline & 17 & $\begin{array}{l}\text { (Net income - Preferred divi- } \\
\text { dend)/Book value of equity }\end{array}$ & $(172-19) / 60$ & NIPCB \\
\hline & 18 & Net income/Sales & $172 / 12$ & NIDSA \\
\hline & & $\begin{array}{l}\text { ((aales - cost or goods sold)/ } \\
\text { Sales }\end{array}$ & $(12-41) / 12$ & GPM \\
\hline \multirow[t]{5}{*}{ Leverage } & 20 & $\begin{array}{l}\text { Book value of long-term debt/ } \\
\text { Book value of equity }\end{array}$ & $9 / 60$ & LTDTE \\
\hline & 21 & Book value of long-term debt/ & & \\
\hline & 22 & $\begin{array}{l}\text { Market value of equity } \\
\text { (Operating income - Deprecia- }\end{array}$ & $9 /\left(24^{\star 2} 25\right)$ & LTDMVE \\
\hline & & & $178 / 15$ & TIEAR \\
\hline & 23 & Total liabilities/Total assets & $181 / 6$ & TLDTA \\
\hline \multirow[t]{3}{*}{ Growtha } & 24 & Growth rate in sales & $\left(12_{-1} / 12_{-3}\right)-1$ & SGROW \\
\hline & 25 & Growth rate in assets & $\left(6_{-1} / 6_{-3}\right)-1$ & AGROW \\
\hline & 26 & Growth rate in employees & $\left(29_{-1} / 29_{-3}\right)-1$ & EGROW \\
\hline Activity & 27 & Sales/Total assets & $12 / 6$ & SADTA \\
\hline
\end{tabular}

${ }^{a}$ Subscripts for growth variables refer to the fiscal year prior to the year of dividend initiation. For example, -1 refers to the fiscal year immediately prior to the year of initiation and -3 refers to three years prior to initiation. 
Profitability. Measures of profitability indicate the success of past and current operations. The greater the profitability of the company, the more likely that it will have cash flows available for dividends. The five profitability ratios measure gross profit margin (GPM), net profit margin (NIDSA), net margin on a cash flow basis (CFDSA), return on assets (NIDTA), and return on equity (NIPCB).

Leverage. A company's ability to pay dividends is affected by its capital structure. To protect debtholders from wealth expropriation, debt contracts frequently include provisions restricting the payment of dividends. Leverage is calculated by three measures of the amount of debt in the company's capital structure-LTDTE (the ratio of long-term debt to book value), LTDMVE (the ratio of long-term debt to the market value of equity), and TLDTA (a broad measure that relates all the liabilities of the company to its reported total assets) - and one measure of the firm's ability to service its debt-TIEAR (the traditional coverage ratio, times interest earned).

Growth. Growth also is related to the investment opportunities of the firm. High-growth companies are less likely than slow-growth companies to have the internal cash flows necessary to pay dividends. The variables are the three-year growth rates in sales, assets, and employees.

Activity. Activity ratios indicate the efficiency with which the firm uses its assets. The ratio used here, SADTA (sales divided by total assets), is also an inverse measure of capital intensity. 



\section{References}

Aharony, Joseph, and Itzhark Swary. 1980. "Quarterly Dividend and Earnings Announcements and Stockholders' Returns: An Empirical Analysis." Journal of Finance, vol. 35, no. 1 (March):1-12.

Allen, Franklin, and Roni Michaely. 1994. "Dividend Policy." Rodney L. White Center for Financial Research (University of Pennsylvania) Working Paper No. 14-94. Philadelphia.

Anderson, M.R. 1973. Cluster Analysis for Applications. New York: Academic Press.

Ang, James. 1987. "Do Dividends Matter? A Review of Corporate Dividend Theories and Evidence." Salomon Brothers Center for the Study of Financial Institutions (New York University) Monograph Series in Finance and Economics, Monograph No. 1987-2. New York.

Asquith, Paul, and David W. Mullins, Jr. 1983. “The Impact of Initiating Dividend Payments on Shareholders' Wealth." Journal of Business, vol. 56, no. 1 (January):77-96.

1986. "Signaling with Dividends, Stock Repurchases, and Equity Issues." Financial Management, vol. 15, no. 3 (Autumn):27-44.

Bolch, Ben W., and Cliff J. Huang. 1974. Multivariate Statistical Methods for Business and Economics. Prentice-Hall International Series in Management. Englewood Cliffs, NJ.

Born, Jeffery A. 1988. "Insider Ownership and Signals: Evidence from Dividend Initiation Announcement Effects." Financial Management, vol. 17, no. 1 (Spring):38-45.

Born, Jeffery A., James Moser, and Dennis Officer. 1988. "Changes in Dividend Policy and Subsequent Earnings." Journal of Portfolio Management, vol. 14, no. 4 (Summer):56-62.

Brickley, James. 1983. "Shareholder Wealth, Information Signaling, and the Specially Designated Dividend." Journal of Financial Economics, vol. 12, no. 2 (August): 187-209.

Brown, Stephen, and Jerold Warner. 1985. "Using Daily Stock Returns: The Case of Event Studies." Journal of Financial Economics, vol. 14, no. 1 (March):331. 
Chung, Kee H., and Charlie Charoenwong. 1991. "Investment Options, Assets in Place, and the Risk of Stocks." Financial Management, vol. 20, no. 3 (Autumn):21-33.

Eades, Kenneth, Patrick Hess, and E. Han Kim. 1985. "Market Rationality and Dividend Announcements." Journal of Financial Economics, vol. 14, no. 4 (December):581-604.

Easterbrook, Frank H. 1984. "Two Agency Cost Explanations of Dividends." American Economic Review, vol. 74, no. 4 (September):650-59.

Fama, Eugene, and Harvey Babiak. 1968. "Dividend Policy: An Empirical Analysis." Journal of the American Statistical Association, vol. 63 (December):113261.

Fama, Eugene, and Kenneth R. French. 1992. "The Cross-Section of Expected Stock Returns." Journal of Finance, vol. 47, no. 2 (June):427-66.

Frankfurter, George, and William R. Lane. 1992. "The Rationality of Dividends." International Review of Financial Analysis, vol. 1, no. 2:115-30.

Healy, Paul M., and Krishna G. Palepu. 1988. "Earnings Information Conveyed by Dividend Initiations and Omissions." Journal of Financial Economics, vol. 21, no. 2 (September):149-76.

1989. "How Investors Interpret Changes in Corporate Financial Policy." Journal of Applied Corporate Finance, vol. 2, no. 3:59-64.

Jayaraman, Narayanan, and Kuldeep Shastri. 1988. "The Valuation Impacts of Specially Designated Dividends." Journal of Financial and Quantitative Analysis, vol. 23, no. 3 (September):301-12.

Jensen, Michael C. 1986. "Agency Costs of Free Cash Flow, Corporate Finance and Takeovers." American Economic Review, vol. 76, no. 2 (May):323-29.

Jensen, Michael C., and William H. Meckling. 1976. "Theory of the Firm: Managerial Behavior, Agency Costs and Ownership Structure." Journal of Financial Economics, vol. 3, no. 4:305-60.

Kane, Alex, Young Ki Lee, and Alan Marcus. 1984. "Earnings and Dividend Announcements: Is There a Corroboration Effect?" Journal of Finance, vol. 39, no. 4 (September):1091-99.

Kennedy, Peter. 1992. A Guide to Econometrics. Cambridge, MA: MIT Press. 
Lang, Larry H.P., and Robert H. Litzenberger. 1989. "Dividend Announcements: Cash Flow Signaling vs. Free Cash Flow Hypothesis." Journal of Financial Economics, vol. 24, no. 1 (September):181-92.

Lintner, John. 1956. "Distribution of Incomes of Corporations among Dividends, Retained Earnings, and Taxes." American Economic Review, vol. 46 (May):97113.

Lipson, Marc L.,.Carlos P. Maquieira, and William L. Megginson. 1995. "Why Do Public Companies Begin Paying Dividends?" Working paper. University of Georgia.

Michaely, Roni, Richard H. Thaler, and Kent L. Womack. 1995. "Price Reactions to Dividend Initiations and Omissions: Overreaction or Drift?" Journal of Finance, vol. 50, no. 2 (June):573-608.

Miller, Merton H., and Franco Modigliani. 1961. "Dividend Policy, Growth and the Valuation of Shares." Journal of Business, vol. 34, no. 4:411-33.

Miller, Merton, and Kevin Rock, 1985. "Dividend Policy under Asymmetric Information." Joumal of Finance, vol. 40, no. 4 (September):1031-51.

Moody's Dividend Record: Annual Cumulative Issue. 1972-89. New York: Moody's Investors Service.

Ofer, Aharon R., and Daniel R. Siegel. 1987. "Corporate Financial Policy, Information, and Market Expectations: An Empirical Investigation of Dividends." Journal of Finance, vol. 42, no. 4 (September):889-911.

Pettit, R. Richardson. 1972. "Dividend Announcements, Security Performance, and Capital Market Efficiency." Journal of Finance, vol. 27, no. 5 (December):993-1007.

Rozeff, Michael. 1982. "Growth, Beta and Agency Costs as Determinants of Dividend Payout Ratios." Journal of Financial Research, vol. 5, no. 3:249-59.

SAS Institute. SAS User's Guide: Statistics. Version 5 Edition. Cary, NC: SAS Institute.

Shen, Yang-pin. 1994. The Information Content of Dividend Initiations. Unpublished doctoral dissertation (Louisiana State University).

Smith, Clifford W., Jr., and Ross L. Watts. 1992. "The Investment Opportunity Set and Corporate Financing, Dividend, and Compensation Policies." Journal of Financial Economics, vol. 32, no. 3 (December):263-92. 
Titman, Sheridan, and Roberto Wessels. 1988. "The Determinants of Capital Structure Choice." Journal of Finance, vol. 43, no. 1 (March):1-19.

Venkatesh, P.C. 1989. "The Impact of Dividend Initiation on the Information Content of Earnings Announcements and Return Volatility." Journal of Business, vol. 62, no. 2 (April):175-97.

Wansley, James W., and William R. Lane. 1987. "A Financial Profile of the Dividend Initiating Firm." Journal of Business Finance \& Accounting, vol. 14, no. 3 (Autumn):425-36.

Wansley, James W., C.F. Sirmans, James Shilling, and Young-jin Lee. 1991. "Dividend Change Announcement Effects and Earnings Volatility and Timing." Journal of Financial Research, vol. 14, no. 1 (Spring):37-50. 